\title{
Chills in music: A systematic review*
}

\author{
Rémi de Fleurian $^{a} \quad$ Marcus T. Pearce ${ }^{a, b}$ \\ ${ }^{a}$ Cognitive Science Research Group, Queen Mary University of London \\ ${ }^{b}$ Center for Music in the Brain, Aarhus University \& Royal Academy of Music
}

\begin{abstract}
Chills are a psychophysiological response which can be experienced when listening to music. They have been of particular interest in scientific research on music because of their association with emotion and pleasure. However, with the literature doubling in size since the last review on the subject, it has become increasingly difficult to gain a broad and integrated understanding of the empirical and theoretical research on musicevoked chills (MECs). Notably, crucial questions remain about the criteria that are necessary and sufficient to characterise MECs. In this article, we systematically review the literature on MECs in order to reconcile diverging opinions and empirical findings on their psychological nature, and to develop a preliminary model that provides a robust framework for future hypothesis-driven research. We explore the context behind current research on MECs, discuss how they relate to emotional and aesthetic responses, assess current empirical measures and paradigms, summarise their physiological and neural correlates, categorise their possible stimulusdriven elicitors, examine how they are affected by individual differences, and evaluate theoretical perspectives about their potential evolutionary causes. We conclude by providing a preliminary model of MECs that suggests different pathways for the experience of MECs, a dataset listing pieces of music reported to elicit MECs in the reviewed literature, and a set of open issues, hypotheses, and recommended approaches for future research.
\end{abstract}

Keywords: chills; piloerection; music; review; model

\section{Contents}

1 Introduction $\quad 2$

2 Methods 4

2.1 Literature search . . . . . . . . . . . . . . . . . . . 4

2.2 Inclusion and exclusion criteria $\ldots \ldots \ldots \ldots \ldots$

2.3 Organisation of findings . . . . . . . . . . . . . . 4

${ }^{*}$ Preprint submitted for peer review. Please do not copy or cite without author's permission. 
3 Results 6

3.1 Context .............................. 6

3.2 Emotion and aesthetics . . . . . . . . . . . . . . 10

3.3 Measures and paradigms . . . . . . . . . . . . . . . . . . 12

3.4 Physiological correlates . . . . . . . . . . . . . . . 16

3.5 Neural correlates . . . . . . . . . . . . . . . . . 18

3.6 Elicitors . . . . . . . . . . . . . . . . . . 22

3.7 Individual differences . . . . . . . . . . . . . . . . . . 27

3.8 Theoretical perspectives on function . . . . . . . . . . . 30

4 Discussion $\quad 34$

4.1 Summary of findings . . . . . . . . . . . . . . . . . . . 35

4.2 Integration of findings . . . . . . . . . . . . . . . . . . . . . . . . . . . . . . . 49

4.3 Framework for future research . . . . . . . . . . . . . . 41

4.4 Conclusion . . . . . . . . . . . . . . . . . . 45

\section{Public significance statement}

Many people experience pleasurable physical sensations during musical listening, commonly referred to as chills. Although there is a fast-growing body of research on chills, their underlying psychological basis remains obscure, partly due to the lack of an integrated theoretical framework for understanding them and generating hypotheses. Our systematic review of 167 research papers on chills from 1980 to 2020 allows us to synthesise a preliminary model of music-evoked chills, which allows for three distinct underlying psychological mechanisms based respectively on arousal, expectation, and emotion.

\section{Introduction}

Chills are a psychophysiological response which can be elicited by music listening. Music-evoked chills (MECs) are often considered to be a pleasurable response, and are therefore used as a convenient indicator of emotional and aesthetic experiences in research on responses to music, because they represent a good alternative to self-reports of subjective pleasure, which can be unreliable, or to physiological measures, which can be non-specific. However, the knowledge base on MECs is rapidly expanding, and as research findings accumulate, it is becoming increasingly difficult to gain a comprehensive and integrated psychological picture of what MECs entail. Notably, crucial questions remain about the criteria that are necessary and sufficient to characterise MECs.

Frequently cited papers describe MECs as "a spreading gooseflesh, hair-on-end feeling that is common on the back of the neck and head and often moves down the spine" (Panksepp, 1995, p. 173), "a particularly intense, euphoric response to music [frequently accompanied] by an autonomic or psychophysiological component" (Blood \& Zatorre, 2001, p. 11818), "intense emotional experiences involving sensations such as goose bumps or shivers down the spine" (Koelsch, 
2010, p. 131), or "a pleasant tingling feeling associated with the flexing of hair follicles, resulting in gooseflesh (technically called piloerection) accompanied by a cold sensation, and sometimes producing a shiver" (Huron \& Margulis, 2010, p. 591).

While superficially similar, these definitions provide pointers to crucial questions which need to be addressed. If MECs are to be used as an indicator of pleasurable experiences, it is important to understand how universal and frequent they are, as well as the nature of their relationship with emotional and aesthetic responses, in order to assess whether or not their relevance is justified, and, if so, clarify their underlying psychological mechanisms. The phenomenology of MECs also deserves clarification, as it is unclear whether empirical findings refer to a single psychophysiological response or to distinct experiences with little common ground. The specificity of the physiological and neural signatures of MECs needs to be explored to establish whether MECs invoke general-purpose mechanisms involved in other functions, such as emotional processing and reward, or are distinguishable from these experiences. Finally, it is necessary to investigate the causes of MECs, both in terms of stimulus-driven properties and individual differences, to better understand their origin, and thereby achieve a broader and more integrated understanding of the empirical and theoretical research on MECs.

MECs are often mentioned in the literature on music and emotion, but at the time of writing, there are only three short reviews entirely dedicated to MECs (Grewe et al., 2009b; L. Harrison \& Loui, 2014; Mori \& Iwanaga, 2014a), one review about MECs and the autonomous sensory meridian response (del Campo \& Kehle, 2016), one review about MECs and music therapy (Tihanyi, 2016), one philosophical essay about MECs and musical aesthetics (Levinson, 2006), two book chapters discussing MECs within the context of musical expectation (Huron \& Margulis, 2010) and of the evolutionary basis of music (Altenmüller et al., 2013), and book chapters on music and emotion which contain subsections on MECs (e.g., Corrigall \& Schellenberg, 2013, 2015; Hodges, 2016; Hunter \& Schellenberg, 2010; Juslin, 2019; McDermott, 2012; Sachs et al., 2018; Stark et al., 2018; Vuust \& Kringelbach, 2010).

Despite referring to the same phenomenon, as evidenced by the fact that these contributions all make reference the same seminal papers on MECs (Blood \& Zatorre, 2001; Goldstein, 1980; Panksepp, 1995; Sloboda, 1991), the topics listed above are very diverse, once again illustrating the need for a clear integration of the 40 years of available research on MECs. The purpose of this article is therefore to systematically review the literature on MECs in order to reconcile diverging opinions and empirical findings on their psychological nature, and to develop a preliminary model that provides a robust framework for future hypothesis-driven research. 


\section{Methods}

We performed a systematic literature search in order to ensure comprehensive coverage. We first outline the search procedure, before going over the inclusion and exclusion criteria, and finally describing how the findings are organised in the next sections of the present review.

\subsection{Literature search}

We searched the databases Web of Science, APA PsycInfo and PsycExtra, PubMed, Scopus, and Google Scholar, using a cut-off date of 30 April 2020, for articles, reviews, conference papers, books, book chapters, and doctoral dissertations about chills and music. All contributions containing the term music and at least one of chills, thrills, frisson, shivers, goosebumps, or piloerection were considered, resulting in 149 records being identified on Web of Science, 85 records on APA PsycInfo and PsycExtra, 47 records on PubMed, and 127 records on Scopus. We also examined the first 100 records returned by Google Scholar for the same search terms, as well as the first 100 records on Google Scholar for contributions dated 2019 or later to ensure we did not miss recent contributions. This process resulted in the identification of 346 unique records.

\subsection{Inclusion and exclusion criteria}

The objective was to include all publications about MECs. We therefore included contributions written in any language, as long as they mentioned both chills and music. The first exclusion criterion accounts for the fact that the queried terms are commonly used in the English language, and therefore appear in many publications which are not about MECs. As a result, 117 irrelevant records were excluded. The second exclusion criterion accounts for the fact that MECs are often briefly mentioned to provide context in broader studies, reviews, or book chapters about music and emotion. As a result, 78 records containing no substantial information about MECs were excluded. In addition, we excluded five records that could not be retrieved, one article written in Japanese that could not be translated online due to issues with character encoding, one corrigendum, the content of which was already reflected in the associated publication, one editorial which simply listed the topics covered in a specific journal issue, and six records because the presented results were also fully covered in subsequent journal articles that were retained in the search. Finally, we included 30 articles and book chapters obtained through backward and forward reference searching, resulting in a total of 167 contributions which represent, to our knowledge, all the available academic literature on MECs.

\subsection{Organisation of findings}

The literature has doubled in size since the reviews by L. Harrison and Loui (2014) and Mori and Iwanaga (2014a) - in this article, we review 83 contributions 


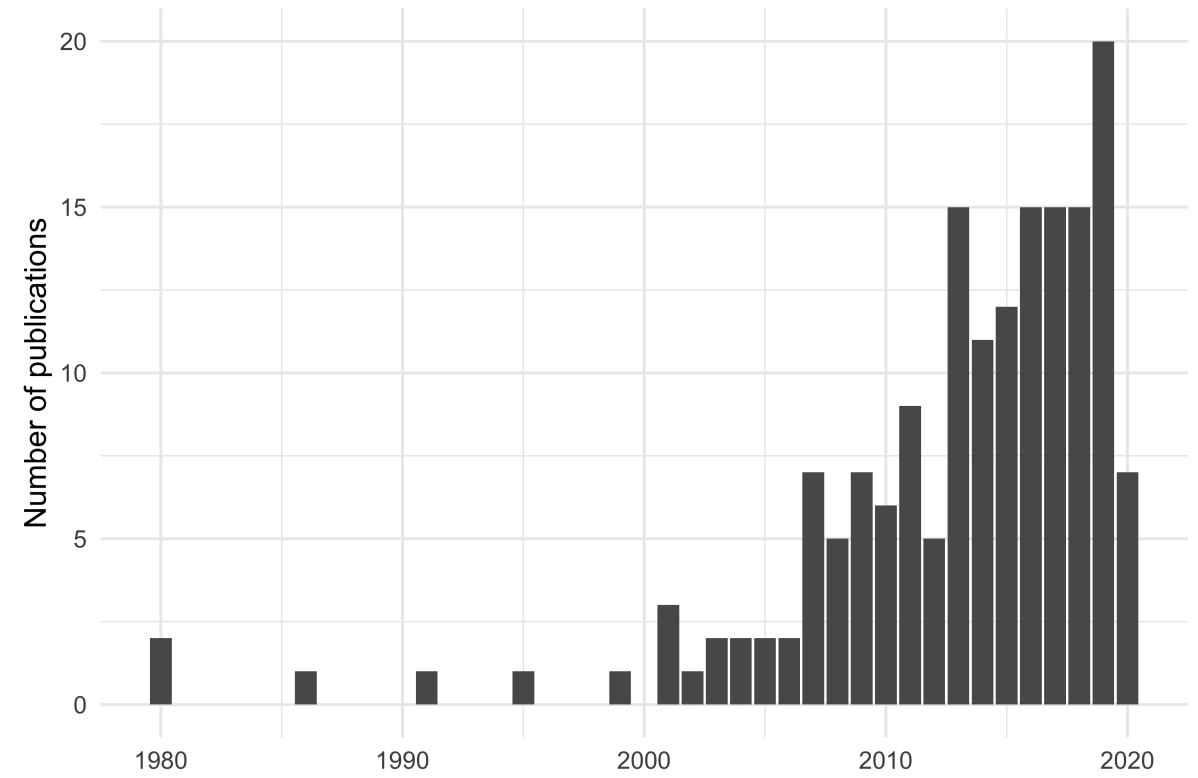

Figure 1: Yearly publication count for research on the topic of music-evoked chills reviewed in this article.

about MECs dated 2014 or prior, and 84 contributions dated 2015 or later (see Figure 1 for the yearly publication count).

The vast majority of publications on MECs contain findings which pertain to several domains of interest. As a consequence, instead of attempting to allocate the publications themselves to meaningful units, we distributed all of their findings across several overarching categories corresponding to these domains. The results are therefore structured as follows. Sections 3.1, 3.2, and 3.3 consider the wider context within which empirical and theoretical research on MECs has been conducted. We begin in Section 3.1 by considering terminological issues, the phenomenological nature of MECs, their prevalence and frequency, and their relationship with other psychological processes. In Section 3.2, we expand on the nature of the relationship between MECs, pleasure, and emotional and aesthetic experience, before assessing subjective and objective ways of measuring MECs, as well as experimental paradigms used in research on MECs in Section 3.3. In the subsequent sections of the paper, we review the empirical literature on the biological basis of MECs, considering associations between MECs, arousal, and physiological responses (Section 3.4), and neural correlates of MECs in the basal ganglia and other brain structures (Section 3.5). We then turn to theoretical considerations regarding the causes of MECs. We review the empirical literature to identify the stimulus-driven causes of MECs and categorise them into acoustic, musical, and emotional elicitors (Section 3.6), examine empirical effects of individual and personality differences on the occurrence of MECs (Section 
3.7 ), and critically evaluate the degree of support provided by the reviewed evidence for current theoretical perspectives on the function of MECs (Section 3.8). These findings are summarised and expanded upon in the discussion, after which we conclude by providing a preliminary model of MECs, a dataset listing pieces of music reported to elicit MECs in the reviewed literature, and a set of hypotheses and recommendations for future research.

\section{Results}

\subsection{Context}

A significant amount of research has focused on identifying exactly what MECs are, but there remains uncertainty about many of their defining aspects. In this section, we review the terminology associated with MECs, their phenomenological nature, their prevalence and frequency, and their relationship with other psychological processes, including emotional and aesthetic responses to music.

\subsubsection{Terminology}

Besides definitions of MECs, an initial source of confusion is the broad range of terms used to refer to the phenomenon. Terms such as musical chills, aesthetic chills, art-elicited chills, shivers, shivers down the spine, psychogenic shivering, thrills, frisson, goosebumps, gooseflesh, goose pimples, piloerection, emotional piloerection, hair standing on end, and skin orgasm, have been used interchangeably over the years, and there is no explicit consensus as to which option should be preferred. L. Harrison and Loui (2014) recommended the use of frisson, a term first used in the context of research on MECs by Huron (2006) and Levinson (2006), which has the advantage of providing a relatively nonspecific way to describe an emotional response with a physiological component, while avoiding the burden of cultural associations present in other terms. While this is a sound recommendation, the term frisson is sparsely used in the literature. We would argue that the need for a unified term of reference outweighs considerations about the colloquial use of the term, and therefore recommend the use of chills $^{1}$, which has quite clearly become the most prevalent term in the recent literature. In this article, we use chills (for the psychophysiological response) and piloerection (for goosebumps specifically) throughout, except when referring to specific findings from authors who used several terms in a single publication.

\subsubsection{Phenomenology}

Regardless of the terminology used, it is important to have a clear and consistent conception of the nature of MECs. This would ensure that participants in

\footnotetext{
${ }^{1}$ Following common usage in the literature, we use the word "chills" as a plural-only, non-countable noun, like clothes or groceries. We feel this is consistent with the difficulty of identifying exactly what would constitute an individual chill (or a definite number of chills) and find it more natural to refer, for example, to an episode of chills.
} 
research on MECs provide responses about the same psychophysiological phenomenon. Failing to do so might lead to inconsistent empirical findings, making interpretation problematic and creating difficulties in relating empirical results between studies. However, identifying a clear and consistent phenomenological description of MECs is not straightforward in the existing literature. Goldstein (1980) provided a thorough starting point through a series of unstructured and structured questionnaires, in which several groups of participants were asked to describe their experience of MECs. The results characterised MECs as a transient, pleasurable response associated with sudden changes in mood or emotion, commonly experienced by a large proportion of the population, and originating primarily in the upper spine or back of the neck, with other common points of origin being shoulders, lower spine, and scalp. Intense occurrences of MECs were described as longer in duration, and radiating to other body areas (most commonly the scalp, arms, shoulders, spine, and face). There are further, varying reports of the location from which MECs originate. The back (or spine), head (or scalp, face, or neck), and arms are the most commonly reported points of origin (Craig, 2005; Goldstein, 1980; Neidlinger et al., 2017; Panksepp, 1995; Wassiliwizky et al., 2015), with occasional mentions of hands or fingers (Craig, 2005), as well as legs (Wassiliwizky et al., 2015).

Interestingly, Craig (2005) made the distinction between points of origin for shivers or tingling (listed above) and piloerection, which was most often reported to begin on the arms, back of the neck, or legs. This raises the important question of whether piloerection should be considered as an integral component of MECs or not. Again, opinions differ. While some definitions of MECs suggest that piloerection is required (Huron \& Margulis, 2010; Panksepp, 1995), most do not (e.g., Blood \& Zatorre, 2001; Goldstein, 1980), and empirical findings support the latter view. In self-reports, piloerection is often reported to happen less often than MECs (Gabrielsson, 2011; Silvia \& Nusbaum, 2011; Sloboda, 1991). In experimental settings, piloerection was only observed in $57 \%$ (Craig, 2005), 40\% (Benedek \& Kaernbach, 2011), 43.1\% (Sumpf et al., 2015), and 40.7\% (Wassiliwizky, Koelsch, et al., 2017) of participants who reported MECs. Seemingly, not all MECs involve piloerection (Craig, 2005), although most (Benedek \& Kaernbach, 2011) or all (Craig, 2005) occurrences of piloerection were found to happen during experiences of MECs. It is therefore likely that MECs, as reported by participants, do not always involve piloerection, although it is possible that experienced MECs might require an intensity threshold to be reached before piloerection can be observed (Sumpf et al., 2015), or that current piloerection detection methods are simply not accurate enough (for an overview of available methods, see Subsection 3.3.2). While relying on self-reported or observed piloerection to study MECs is tempting, due to the objectivity it provides, it seems more appropriate at this stage to combine such an approach with self-reports of MECs (e.g., Wassiliwizky, Koelsch, et al., 2017), in order to avoid biasing research away from what people actually experience as MECs (Maruskin et al., 2012). 


\subsubsection{Prevalence and frequency}

While $79 \%$ of the 249 participants who completed Goldstein's (1980) questionnaires reported having experienced MECs in the past, additional figures about the prevalence of the ability to experience MECs are available in the literature: $90 \%$ of a sample of 83 respondents for experiencing shivers down the spine at least once in the past five years (Sloboda, 1991, also reporting $62 \%$ for goose pimples and $31 \%$ for trembling), over $80 \%$ of 186 respondents for experiencing shivers down the spine or goose pimples at least rarely over the past five years (Mlejnek, 2013), or $86 \%$ of 828 respondents for experiencing MECs with some regularity (Panksepp, 1995). In a survey of 196 people by Nusbaum and Silvia (2011), $8 \%$ of respondents never or rarely experienced MECs, and in a survey of 188 people by Silvia and Nusbaum (2011), $11.2 \%, 9.6 \%$, and $23.5 \%$ never or rarely experienced chills down the spine, goosebumps, and feeling hair standing on end, respectively, although it is worth keeping in mind that for the latter study, only half of the reports were about experiences when listening to music. There are further figures available in the literature, showing MECs as generally less prevalent in experimental settings (e.g., Colver \& El-Alayli, 2016; Grewe et al., 2009a; Konečni et al., 2007), but when looking at prevalence, it makes sense to consider only results from surveys of a reasonably representative sample of the population, since participants in lab experiments have most often been recruited for their ability to experience MECs, but might also not have been able to experience MECs under experimental conditions for a variety of reasons. Limitations remain, due to the fact that people interested in taking surveys about reactions to music might not be fully representative of the population, but from these results, it is reasonable to assume that $90 \%$ is an upper limit for the proportion of the population that has the ability to experience MECs. Interestingly, when providing free reports of their strongest, most intense experience of music, respondents spontaneously included MECs or shivers in $10 \%$ of their reports, and piloerection or gooseflesh in 5\% of their reports (Gabrielsson, 2011).

In terms of frequency, those who experience MECs seem to do so quite regularly. MECs are reported as the most frequent (Sloboda, 1991) or second most frequent physical response to music, behind tears (Gabrielsson, 2011; Scherer et al., 2001), and happen with some regularity for most people (Panksepp, 1995), ranging from every week to every few months (Bannister, 2020a; Goldstein, 1980). For instance, during a week of experience sampling, $81 \%$ of respondents reported having at least one experience of MECs, and reported MECs in $14 \%$ of the occurrences of listening to music (Nusbaum et al., 2014).

\subsubsection{Relation to other psychological processes}

Another step in better understanding MECs is to examine the role they play in emotional and aesthetic responses to music, with studies in which such responses are classified using content analysis, factor analysis, or principal component analysis. Panzarella (1980) found that MECs belong to one of the four major dimensions which can describe intense, joyous experiences of listening to music 
or looking at visual art. This dimension, called motor-sensory ecstasy, was found to be mostly associated with the climactic stage of an aesthetic experience. Scherer et al. (2001) coded qualitative reports of the last time respondents were emotionally affected by a piece of music, and assigned MECs and piloerection to one of five major emotion components, called physiological symptoms. Gabrielsson and Wik (2003), as a part of their work on identifying the components and causes of strong experiences related to music (Gabrielsson, 2001), found that in descriptions of the strongest, most intense experiences of music reported by almost 900 participants, MECs and piloerection were best coded and classified as physiological reactions, a sub-component of physical reactions and behaviours. Zentner et al. (2008), in a series of studies aimed at identifying and validating a taxonomy of musically induced emotions for the development of the Geneva Emotional Music Scale, retained MECs as one of 40 items present in a secondorder model of musical emotions. MECs were found to belong to one of nine first-order factors, transcendence, which itself belongs to one of three second-order factors, sublimity. Silvia and Nusbaum (2011) found that out of twelve unusual aesthetic states, the three states related to MECs (chills down the spine, hair standing on end, goosebumps) made up one of three factors, simply called chills. The three factors (chills, touched, absorption) all loaded strongly on a single higher-order factor for aesthetic experience. In developing the Barcelona Musical Reward Questionnaire, Mas-Herrero et al. (2013) included an item about MECs as one of twenty items that best capture individual differences in how people experience reward associated with music. This item loaded highly on one of five factors, named emotional evocation. Bannister (2020a) coded a large number of reports of how surveyed participants felt during the experience of MECs, and identified emotions and feelings and physical reactions as the two themes accounting for most responses. Finally, Cotter et al. (2018) used MECs as an item in a twenty-four-item questionnaire about feeling like crying in response to music. The two resulting latent classes were named awe and sad, with higher levels of experiencing MECs for the former than for the latter - a finding that was replicated in a subsequent study (Cotter et al., 2019).

Two contributions using similar approaches deserve particular consideration, due to their exclusive focus on the experience of chills. Maruskin et al. (2012) put forward a convincing argument that chills might consist of a set of distinct phenomena with different psychological and biological bases. This motivated an extensive body of work in which a wide range of self-reports of the experience of chills associated with emotionally significant events were analysed in order to gain a better understanding of chills as a psychological construct. It was found that chills are best understood as comprising four conceptually distinct sensations: goosebumps, tingling (grouped together as a higher order factor, goosetingles, associated with positive affective states), coldness, and shivers (grouped together as coldshivers, associated with negative affective states). Similarly, Bannister (2019), using a quantitative approach, investigated whether chills should be considered as a single psychological construct, reflective of intense pleasure and emotion, or as an umbrella term for distinct experiences. Analysis of responses to questionnaire items revealed that chills can be conceptualised as comprising 
three categories: warm chills (associated with positively valenced feelings and physical responses), cold chills (associated with negatively valenced feelings and physical responses), and moving chills (associated with more ambiguous responses, such as tears, feeling a lump in the throat, affection, or tenderness, among others). Although it is tempting to draw parallels between the categories identified by Maruskin et al. (2012) and Bannister (2019), they are not directly comparable because they were derived from responses to emotionally significant events in one case, and aesthetic stimuli in the other. Regardless, these considerations are of particular importance, because if chills are indeed a collection of phenomenologically and psychologically distinct experiences, failing to distinguish between them might lead to null, conflicting, or misleading results (Bannister, 2019; Maruskin et al., 2012). Note, however, that the vast majority of research on MECs continues to treat them as a single construct.

It is worth noting that several studies reviewed in this section and in the rest of this article do not exclusively pertain to reactions to music. These studies were included if they counted music as one of several investigated modalities, or if they reported results relevant to research on MECs. For instance, chills are known to occur in response to visual stimuli (Bannister, 2019; Goldstein, 1980; Grewe et al., 2011; Maruskin et al., 2012; Panzarella, 1980; Silvia \& Nusbaum, 2011; Sumpf et al., 2015; Wassiliwizky, Jacobsen, et al., 2017), and also to text, poetry, film audio, sounds (human, animal, natural, and technical), speech, beauty in nature, touch, smell, taste, memories, and virtual reality environments, among others (Benedek \& Kaernbach, 2011; Bériachvili, 2016; Goldstein, 1980; Grewe et al., 2011; Konečni et al., 2007; Quesnel \& Riecke, 2018; Schoeller \& Eskinazi, 2019; Schurtz et al., 2012; Wassiliwizky, Koelsch, et al., 2017). In cases where occurrences of chills were compared across modalities, there is no consensus as to whether music should be considered the most potent elicitor (Goldstein, 1980; Sumpf et al., 2015) or not (Bannister, 2019; Benedek \& Kaernbach, 2011; Grewe et al., 2011; Schurtz et al., 2012). Two of these studies set out to answer that question explicitly through surveys (Goldstein, 1980; Schurtz et al., 2012), while the other analyses of this effect simply compared occurrences of chills across the specific sets of stimuli used in each study, making it difficult to assess how generalisable these results are.

\subsection{Emotion and aesthetics}

As discussed in the previous section, MECs have been fairly consistently classified as components of emotional or aesthetic experiences. However, there is also considerable discussion about what constitutes such experiences, and therefore their specific relationship with MECs deserves clarification. In this section, we review how MECs are associated with emotional responses, pleasure, and aesthetic responses. 


\subsubsection{Emotional response}

MECs are often discussed in book chapters on music and emotion, either as a physiological response which can accompany intense musical emotions (Juslin, 2016), or as a strong, specific emotional reaction to music (Eerola, 2018; Hunter \& Schellenberg, 2010). To disentangle these interpretations, it is useful to refer to definitions of musical emotions. MECs show some of the qualities of emotional states, as defined by Juslin et al. (2010), because they can involve a subjective experience, observed in self-reports of emotional reactions to music (see Subsection 3.1.4), and because they have been shown to involve physiological arousal, both in terms of measured physiological responses and self-reported arousal (see Section 3.4). However, MECs do not clearly exhibit other characteristic components of emotional states, such as motor expression or action tendency (Juslin et al., 2010; Scherer, 2009), and they can be associated with positive or negative valence (e.g., Bannister, 2019; Maruskin et al., 2012). These considerations suggest that, instead of being considered as an emotion category or emotional state per se, MECs are best understood as a psychophysiological response which can form part of a range of emotional states (Grewe et al., 2011; Juslin, 2019).

\subsubsection{Pleasure}

In this article, we make a distinction between pleasure experienced while listening to music and positively valenced music-evoked emotion (see E. Schubert, 2013). It is perfectly possible, for example, to experience sadness while listening to a piece of music but also to find that experience pleasurable. Most studies of MECs have treated them as a pleasurable response to music. Interestingly, this notion permeated the early literature on MECs despite limited evidence at the time that MECs were indeed associated with pleasure (Blood \& Zatorre, 2001; Goldstein, 1980). Since then, research has confirmed that such an association exists, as shown by an analysis of qualitative reports in an extensive survey (Bannister, 2020a), by significant increases in pleasure occurring immediately prior to the onset of MECs and peak pleasure coinciding with MECs (Salimpoor et al., 2009), by a joint increase in pleasure and occurrence of chills when watching video clips preceded by a meaningful statement as opposed to an incoherent statement (Schoeller, Eskinazi, \& Garreau, 2018; Schoeller \& Perlovsky, 2016), by MECs playing a role in driving music preference (Schäfer \& Sedlmeier, 2010, 2011), and more generally, by a documented association between MECs and self-reports of increased subjective pleasure when listening to music (Grewe et al., 2011; Grewe et al., 2009a; Grewe et al., 2007; Mori \& Iwanaga, 2014b, 2015, 2017; Salimpoor et al., 2011; Salimpoor et al., 2009; Sumpf et al., 2015). Interestingly, displeasurable chills can also be experienced in response to unpleasant sounds (Grewe et al., 2011; Grunkina et al., 2017; Halpern et al., 1986; Klepzig et al., 2020). Given that chills can form a part of unpleasant experiences, it is possible

that MECs are generally experienced as pleasurable because music listening itself is generally a pleasurable activity (Dubé \& Le Bel, 2003). 


\subsubsection{Aesthetic response}

Since MECs are generally experienced as pleasurable, their role in aesthetic responses also deserves clarification (Hodges, 2016). MECs have been referred to as one of several indices of aesthetic experiences of music (E. Schubert et al., 2016; Vuust \& Kringelbach, 2010). As noted in Subsection 3.1.4, previous questionnaires and qualitative reports about aesthetic responses to music have included MECs (Panzarella, 1980; Silvia \& Nusbaum, 2011). To better understand this relationship, we need a precise definition of the aesthetic appreciation of music. Here, we follow Levinson (2009) in characterising aesthetic appreciation as a positive estimation based on an intrinsically pleasurable experience arising from attention directed to the form and content of a piece of music. Based on the range of psychological components thought to be involved in aesthetic appreciation (see Leder et al., 2004; Leder \& Nadal, 2014, for another extensive, multi-component model), it seems unlikely that MECs should be considered as an aesthetic experience in and of themselves. Rather, a more promising interpretation would be that MECs can contribute to aesthetic experiences, because they constitute a pleasurable response to some musical properties (see Section 3.6). Indeed, in a philosophical essay about MECs, Levinson (2006) argues that they provide a signal that something significant happened in the music - in other words, a focuser of attention - and in so doing, make a valuable contribution to wholly experiencing a piece of music, through a culmination of cognitive, emotional, physiological, and behavioural responses. According to E. Schubert et al. (2016), this contribution, and that of other subjective experiences evoked by music (or internal locus affects), is what motivates people to seek out aesthetic experiences. Many researchers have considered MECs to form an optional, rather than a central, component in the aesthetic experience of music (e.g., Bériachvili, 2016; Brattico et al., 2013; Gabrielsson et al., 2016; Konečni, 2007), and this is a view we share, in light of the reviewed literature.

\subsection{Measures and paradigms}

Most of the early research on MECs focused on the analysis of survey answers. As the need for experimental data grew in order to adequately investigate MECs occurring in response to specific stimuli, the methods used in lab or online studies became increasingly diverse. These methods are described in this section, with a focus on self-reports and objective measures of MECs (summarised in Table 1), as well as experimental paradigms (summarised in Table 2) which have dominated the empirical literature on MECs.

\subsubsection{Self-reports}

When listening to music, MECs can either be self-reported or observed, and recorded retrospectively or continuously. A popular and convenient way to measure MECs is to rely completely on retrospective self-reports about the frequency or intensity of MECs (see Table 1 for a list of papers using this 
approach), generally collected with a short questionnaire after each trial. This has the advantage of requiring virtually no resources, but is also one of the least informative ways to record MECs. As a more detailed approach, continuous self-reports allow researchers to collect data on the specific timing of the onsetand sometimes offset - of MECs, with the exception of two studies in which participants were asked to keep a count of experiences of MECs on a scratch sheet (Balteș et al., 2011; Balteș \& Miu, 2014). In their simplest form, continuous self-reports can be collected by asking participants to raise their finger or hand for the duration of experienced MECs (Craig, 2005; Goldstein, 1980; Konečni et al., 2007; Panksepp, 1995). Most commonly, however, participants report MECs by pressing on a button (see Table 1), sometimes in conjunction with continuous self-reports of valence and arousal, using bespoke interfaces such as EMuJoy (Nagel et al., 2007). In a few cases, an analogue slider (Bannister \& Eerola, 2018) or a pressure-sensitive handle (Grunkina et al., 2017; Klepzig et al., 2020) have been used instead of a button to collect continuous ratings of MECs intensity, rather than a binary response about the occurrence of MECs.

An important methodological consideration in studies that use button presses for MECs and collect skin conductance response data is whether the act of pressing a button raises skin conductance response by itself. This has been consistently demonstrated not to be the case (Bannister, 2020b; Colver \& ElAlayli, 2016; Grewe et al., 2011; Grewe et al., 2009a; Grewe et al., 2007; Guhn et al., 2007; Mori \& Iwanaga, 2014b, 2015; Rickard, 2004; Salimpoor et al., 2009). Relatedly, several studies have validated button presses by only including the reported MECs in the analysis if they are accompanied by an increase in skin conductance response (Bannister, 2020b; Beier et al., 2020; Colver \& El-Alayli, 2016; Egermann et al., 2011; Grewe et al., 2007; Mori \& Iwanaga, 2014b). This approach has the advantage of not exclusively relying on self-reports, but considering the current lack of understanding regarding the exact relationship between MECs and skin conductance response (see Subsection 3.4.1), it might also lead to valid occurrences of MECs being discarded, depending on the chosen threshold.

\subsubsection{Objective measures}

The ideal way to record MECs would consist of an objective and continuous measure. Panksepp and Bernatzky (2002) made a brief reference to an inconclusive attempt at measuring MECs using thermal imaging of the skin surface, following a suggestion to use objective measures in an earlier publication (Panksepp, 1995). The authors concluded that directly measuring piloerection might be more appropriate, as previously suggested by Sloboda (1991). This can be done manually, as was the case in a study in which participants placed their arm through a curtain, and observers noted the onset and offset of piloerection (Craig, 2005), or automatically, using devices which can monitor piloerection.

The most notable example of such devices is the Goosecam (Benedek et al., 2010), an optical device which can be roughly described as a camera embedded in a box that blocks external light, recording the skin of the forearm-or lower 


\begin{tabular}{|c|c|c|}
\hline Type & Method & Papers \\
\hline $\begin{array}{l}\text { Retrospective } \\
\text { self-reports }\end{array}$ & & $\begin{array}{l}\text { Bannister (2019), Blood and Zatorre (2001), Carr and Rickard (2016), Chabin et al. (2020), } \\
\text { Goodchild et al. (2019), Honda et al. (2020), Jaimovich et al. (2013), Ji et al. (2019), Juslin et al. } \\
\text { (2014), Park et al. (2019), Polo (2017), Schäfer and Sedlmeier (2011), Schoeller and Perlovsky } \\
\text { (2016), Schoeller, Eskinazi, and Garreau (2018), Schoeller and Eskinazi (2019), Seibt et al. (2017) } \\
\text { Silvia et al. (2015), Solberg and Dibben (2019), Strick et al. (2015), Wassiliwizky et al. (2015), } \\
\text { Weth et al. (2015) }\end{array}$ \\
\hline \multirow{5}{*}{$\begin{array}{l}\text { Continuous } \\
\text { self-reports }\end{array}$} & Raising finger or hand & Craig (2005), Goldstein (1980), Konečni et al. (2007), Panksepp (1995) \\
\hline & Scratch sheet & Balteș et al. (2011), Balteș and Miu (2014) \\
\hline & Button & $\begin{array}{l}\text { Bannister (2020b), Beier et al. (2020), Colver and El-Alayli (2016), Egermann et al. (2011), } \\
\text { Ferreri et al. (2019), Grewe et al. (2007), Grewe et al. (2009a), Grewe et al. (2011), Guhn et al. } \\
\text { (2007), Laeng et al. (2016), Mas-Herrero et al. (2014), Mori and Iwanaga (2014b), Mori and } \\
\text { Iwanaga (2015), Mori and Iwanaga (2017), Nagel et al. (2008), Polo (2017), Rickard (2004), Sachs } \\
\text { et al. (2016), Salimpoor et al. (2009), Salimpoor et al. (2011), T. W. Schubert et al. (2018), Seibt } \\
\text { et al. (2018), Starcke et al. (2019), Sutherland et al. (2009), Wassiliwizky, Koelsch, et al. (2017), } \\
\text { Zickfeld, Schubert, Seibt, Blomster, et al. (2019) }\end{array}$ \\
\hline & Analogue slider & Bannister and Eerola (2018) \\
\hline & $\begin{array}{l}\text { Pressure-sensitive } \\
\text { handle }\end{array}$ & Grunkina et al. (2017), Klepzig et al. (2020) \\
\hline \multirow{3}{*}{$\begin{array}{l}\text { Objective } \\
\text { measures }\end{array}$} & Direct observation & Craig (2005) \\
\hline & Goosecam & $\begin{array}{l}\text { Benedek et al. (2010), Benedek and Kaernbach (2011), Quesnel and Riecke (2018), Sumpf et al. } \\
\text { (2015), Wassiliwizky, Jacobsen, et al. (2017), Wassiliwizky, Koelsch, et al. (2017) }\end{array}$ \\
\hline & $\begin{array}{l}\text { Conductive polymer } \\
\text { sensor }\end{array}$ & Kim et al. (2014) \\
\hline
\end{tabular}

Table 1: Measures of music-evoked chills

leg in some later studies - from a close distance. LED lights shine on the skin at an angle from within the box, allowing goosebumps to cast a shadow on the skin. Images are then processed with a MATLAB toolbox using a discrete Fourier transform to provide a continuous measure of piloerection. A piloerection event occurs if the computed value exceeds an arbitrarily set threshold - usually defined in terms of the number of standard deviations away from a baseline recording - for a specified number of consecutive frames. The Goosecam has been tested in one participant who had voluntary control over piloerection (for an interesting exploratory investigation of this phenomenon, see Heathers et al., 2018), and was found to provide observations consistent with human judges (Benedek et al., 2010). It has since been used in several studies (see Table 1).

Another piloerection-monitoring device was proposed by Kim et al. (2014), and consists of a very thin, flexible, and compact sensor made of conductive polymer, which can be affixed to the skin to measure the physical deformation of its surface when goosebumps occur. The device was tested and validated by the authors, but while it represents an elegant solution, it remains unused in other studies to date, possibly because it requires resources which are less accessible than those needed to build a Goosecam.

\subsubsection{Paradigms}

Careful study design is required to investigate the different aspects of MECs. A popular approach initially used by Blood and Zatorre (2001) and in many 
later studies (see Table 2) requires participants to provide songs during which they often experience MECs. They are then asked to listen to these songs and to songs provided by other participants, which act as a control. This has the clear advantages of ensuring that genuine MECs are experienced, and excluding the possibility that the effects observed were simply due to the properties of each piece of music, since one participant's MECs-inducing stimulus is another participant's control stimulus. Common findings in these studies are that participants experience more MECs when listening to self-selected music, highlighting possible effects of familiarity (see Subsection 3.6.5), stylistic preference (see Subsection 3.7.2), and meaning (see Subsection 3.6.3), and demonstrating that MECs are not caused by stimulus-driven properties alone. While this study design has been particularly fruitful because MECs are often considered to be highly idiosyncratic (Nusbaum et al., 2014; Panksepp, 1995), it is important to bear in mind that MECs most likely involve an interaction between listener, context, and music (see Subsection 4.1.6).

Other studies have compared or combined responses to self-selected stimuli and to stimuli selected by the researchers (either arbitrarily or following a pre-selection procedure), used experimenter-selected stimuli only, or participantselected stimuli only (see Table 2). Each of these approaches have distinct advantages and disadvantages, such as the degree of control over what the participants listen to, or how familiar they are with each piece of music. More specifically, experimenter-selected stimuli allow precise control over stimulus properties and familiarity, but may not always elicit MECs, whereas participantselected stimuli are very likely to induce genuine MECs, at the cost of lower control over stimulus properties or familiarity.

Other paradigms provide better opportunities for making precise causal inferences, through direct manipulation of the stimuli (Bannister, 2020b; Bannister \& Eerola, 2018; Honda et al., 2020; Juslin et al., 2014; Park et al., 2019), administration of substances thought to alter the experience of MECs (Ferreri et al., 2019; Goldstein, 1980; Starcke et al., 2019), repeated presentation of the same stimuli to the same participant (Grewe et al., 2007), or more broadly, through the a priori design of clearly distinct experimental conditions (see Table 2). Note that here, we are referring to causal paradigms, and not necessarily to knowledge about what causes MECs, which is why these studies are discussed in different sections of this article based on how relevant their findings are to each section. Such causal designs are clearly capable of providing more robust insight into MECs than experiments providing only correlational evidence, although they come with their own set of challenges, such as manipulating stimuli while maintaining ecological validity and avoiding the introduction of confounding factors.

While less relevant to this review, it is worth mentioning a small set of studies that have used MECs as an independent variable, leading to findings that MECs led to improved communication and heightened self-perception in a music therapy context (Lee, 2008), as also hypothesised by Tihanyi (2016), had no effect on memory performance as measured by image recall (Carr \& Rickard, 2016) or on craving reduction in abstinent individuals with alcohol use disorder 


\begin{tabular}{|c|c|c|}
\hline Type & Design & Papers \\
\hline \multirow[t]{4}{*}{$\begin{array}{l}\text { No } \\
\text { manipulation }\end{array}$} & $\begin{array}{l}\text { Experimenter-selected } \\
\text { music only }\end{array}$ & $\begin{array}{l}\text { Baltess et al. (2011), Baltes and Miu (2014), Bannister (2019), Colver and El-Alayli (2016), } \\
\text { Grewe et al. (2011), Grunkina et al. (2017), Guhn et al. (2007), Jaimovich et al. (2013), Ji et al. } \\
\text { (2019), Klepzig et al. (2020), Konečni et al. (2007), Polo (2017), Schäfer and Sedlmeier (2011), } \\
\text { T. W. Schubert et al. (2018), Seibt et al. (2017), Seibt et al. (2018), Silvia et al. (2015), Solberg } \\
\text { and Dibben (2019), Strick et al. (2015), Wassiliwizky et al. (2015), Zickfeld, Schubert, Seibt, } \\
\text { Blomster, et al. (2019) }\end{array}$ \\
\hline & $\begin{array}{l}\text { Participant-selected } \\
\text { music only }\end{array}$ & Craig (2009), Fukui and Toyoshima (2013), Wassiliwizky, Jacobsen, et al. (2017) \\
\hline & $\begin{array}{l}\text { Participant- vs. } \\
\text { experimenter-selected } \\
\text { music }\end{array}$ & $\begin{array}{l}\text { Benedek and Kaernbach (2011), Carr and Rickard (2016), Craig (2005), Grewe et al. (2007), } \\
\text { Mas-Herrero et al. (2014), Nagel et al. (2008), Panksepp (1995), Quesnel and Riecke (2018), } \\
\text { Rickard (2004), Weth et al. (2015), Wassiliwizky, Koelsch, et al. (2017) }\end{array}$ \\
\hline & $\begin{array}{l}\text { Participant-selected vs. } \\
\text { other participants' music }\end{array}$ & $\begin{array}{l}\text { Blood and Zatorre (2001), Laeng et al. (2016), Mori and Iwanaga (2014b), Mori and Iwanaga } \\
\text { (2015), Mori and Iwanaga (2017), Sachs et al. (2016), Salimpoor et al. (2009), Salimpoor et al. } \\
\text { (2011), Sumpf et al. (2015) }\end{array}$ \\
\hline \multirow[t]{6}{*}{ Manipulation } & Stimulus manipulation & $\begin{array}{l}\text { Bannister and Eerola (2018), Bannister (2020b), Honda et al. (2020), Juslin et al. (2014), Park } \\
\text { et al. (2019) }\end{array}$ \\
\hline & Stimulus comparison & Beier et al. (2020), Goodchild et al. (2019) \\
\hline & Group comparison & Beier et al. (2020), Grewe et al. (2009a) \\
\hline & Treatment comparison & $\begin{array}{l}\text { Egermann et al. (2011), Schoeller and Perlovsky (2016), Schoeller, Eskinazi, and Garreau (2018), } \\
\text { Sutherland et al. (2009) }\end{array}$ \\
\hline & Longitudinal & Grewe et al. (2007) \\
\hline & Neurochemical & Ferreri et al. (2019), Goldstein (1980), Starcke et al. (2019) \\
\hline \multirow[t]{2}{*}{ Other } & $\begin{array}{l}\text { Chills as independent } \\
\text { variable }\end{array}$ & $\begin{array}{l}\text { Carr and Rickard (2016), Fukui and Toyoshima (2014), Konečni et al. (2007), Lee (2008), } \\
\text { Mathis and Han (2017), Park et al. (2019) }\end{array}$ \\
\hline & $\begin{array}{l}\text { Chills induction through } \\
\text { physical means }\end{array}$ & Fukushima and Kajimoto (2012), Ishikawa et al. (2019), Schoeller et al. (2019) \\
\hline
\end{tabular}

Table 2: Experimental paradigms used in research on music-evoked chills

(Mathis \& Han, 2017), had an effect on gait, as seen by increased cadence and stride length, and reduced stride time (Park et al., 2019), did not improve mood or increase generosity, helpfulness, or prosocial behaviour (Konečni et al., 2007), but contradictorily, did promote altruistic behaviour (Fukui \& Toyoshima, 2014). Three devices have also been designed in an attempt to induce chills, through electrostatic force (Fukushima \& Kajimoto, 2012) or coldness (Ishikawa et al., 2019; Schoeller et al., 2019), with the purpose of enhancing emotional experiences.

\subsection{Physiological correlates}

Being involved in emotional reactions (see Subsection 3.2.1), MECs are associated with autonomic nervous system activity (Kreibig, 2010), and are therefore accompanied by a set of physiological responses which have been studied extensively. We review these responses by examining how electrodermal, cardiac, and other physiological measures are associated with MECs (see Table 3 for a summary).

\subsubsection{Skin measures}

Electrodermal activity is typically decomposed into its tonic component, skin conductance level, reflecting slow, smooth changes in baseline activity, and its phasic component, skin conductance response, reflecting rapidly changing, 
event-related activity. Skin conductance level was found to increase around the onset of MECs, either shortly before they occur (Grewe et al., 2009a) or shortly after (Benedek \& Kaernbach, 2011; Mori \& Iwanaga, 2017), though a comparable number of studies found no effects of MECs on this measure (Baltes, et al., 2011; Carr \& Rickard, 2016; Jaimovich et al., 2013; Schäfer \& Sedlmeier, 2011). The consensus is much more pronounced for skin conductance response, with many studies reporting associations with MECs(see Table 3), and only three not detecting such associations (Blood \& Zatorre, 2001; Carr \& Rickard, 2016; Jaimovich et al., 2013). Specifically, skin conductance response has been found to increase shortly before (Egermann et al., 2011; Grewe et al., 2009a; Salimpoor et al., 2009) or after (Benedek \& Kaernbach, 2011; Grewe et al., 2011; Mori \& Iwanaga, 2017) the onset of MECs, and to peak during (Craig, 2005; Salimpoor et al., 2009) or shortly after (Grewe et al., 2009a; Mori \& Iwanaga, 2017) MECs. In some of these studies, however, self-reported MECs were only considered for analysis if accompanied by an increase in skin conductance response (see Subsection 3.3.1), which might have biased the results to some extent. Finally, peripheral skin temperature was found in some studies to decrease during MECs (Salimpoor et al., 2009) or with MECs intensity (Salimpoor et al., 2011), although others found no such association (Blood \& Zatorre, 2001; Craig, 2005; Rickard, 2004).

\subsubsection{Heart measures}

Increases in heart rate (or decreases in interbeat interval - an inversely related variable) have generally been found to be associated with MECs, though, again, these findings have not always been replicated (see Table 3). Interestingly, in one study, heart rate was found to increase only for MECs that involve piloerection (Sumpf et al., 2015). Decreases in blood volume pulse amplitude (Benedek \& Kaernbach, 2011; Salimpoor et al., 2011; Salimpoor et al., 2009), increases in $E_{K}$, a specific ratio of cardiac amplitudes in the resting electrocardiogram associated with emotionality (Sumpf et al., 2015), respiratory sinus arrhythmia, and power in the low frequency of heart rate variability (Baltes et al., 2011) have also been associated with MECs, while no effects were found for heart rate variability (Carr \& Rickard, 2016), systolic blood pressure, diastolic blood pressure, power in the very low frequency of heart rate variability, and the ratio between low and high frequency powers of heart rate variability (Balteș et al., 2011).

\subsubsection{Other measures}

Empirical evidence is mixed on the relationship between MECs and an increase in respiration rate, with some studies finding supporting evidence, and others failing to identify such a relationship (see Table 3). Respiration depth, however, has been found to increase in all (Benedek \& Kaernbach, 2011; Blood \& Zatorre, 2001; Grewe et al., 2009a) but one study (Mori \& Iwanaga, 2017). Muscle tension, as measured by electromyography, increased when listening to self-selected music known to induce MECs (Blood \& Zatorre, 2001), but was not reported to 


\begin{tabular}{|c|c|c|}
\hline System & Measure & Papers \\
\hline \multirow[t]{3}{*}{ Skin } & $\begin{array}{l}\text { Skin conductance } \\
\text { level }\end{array}$ & $\begin{array}{l}\text { Increase: Benedek and Kaernbach (2011), Grewe et al. (2009a), Mori and Iwanaga (2017) } \\
\text { No effect: Balteș et al. (2011), Carr and Rickard (2016), Jaimovich et al. (2013), Schäfer and Sedlmeier } \\
\text { (2011) }\end{array}$ \\
\hline & $\begin{array}{l}\text { Skin conductance } \\
\text { response }\end{array}$ & $\begin{array}{l}\text { Increase: Bannister and Eerola (2018), Benedek and Kaernbach (2011), Craig (2005), Egermann et al. } \\
\text { (2011), Grewe et al. (2007), Grewe et al. (2009a), Grewe et al. (2011), Guhn et al. (2007), Klepzig et al. } \\
\text { (2020), Mas-Herrero et al. (2014), Mori and Iwanaga (2014b), Mori and Iwanaga (2015), Mori and Iwanaga } \\
\text { (2017), Polo (2017), Rickard (2004), Sachs et al. (2016), Salimpoor et al. (2009), Salimpoor et al. (2011) } \\
\text { Effect (direction not specified): Grewe et al. (2007) } \\
\text { No effect: Blood and Zatorre (2001), Carr and Rickard (2016), Jaimovich et al. (2013) }\end{array}$ \\
\hline & $\begin{array}{l}\text { Peripheral skin } \\
\text { temperature }\end{array}$ & $\begin{array}{l}\text { Decrease: Salimpoor et al. (2009), Salimpoor et al. (2011) } \\
\text { No effect: Blood and Zatorre (2001), Craig (2005), Rickard (2004) }\end{array}$ \\
\hline \multirow[t]{3}{*}{ Heart } & Heart rate & $\begin{array}{l}\text { Increase: Benedek and Kaernbach (2011), Blood and Zatorre (2001), Grewe et al. (2009a), Guhn et al. } \\
\text { (2007), Mas-Herrero et al. (2014), Polo (2017), Sachs et al. (2016), Salimpoor et al. (2009), Salimpoor et al. } \\
\text { (2011), Sumpf et al. (2015) } \\
\text { No effect: Baltes et al. (2011), Carr and Rickard (2016), Grewe et al. (2011), Jaimovich et al. (2013), Mori } \\
\text { and Iwanaga (2017), Rickard (2004), Schäfer and Sedlmeier (2011) }\end{array}$ \\
\hline & $\begin{array}{l}\text { Blood volume pulse } \\
\text { amplitude }\end{array}$ & Decrease: Benedek and Kaernbach (2011), Salimpoor et al. (2009), Salimpoor et al. (2011) \\
\hline & $\begin{array}{l}\text { Lesser-used } \\
\text { measures }\end{array}$ & See Subsection 3.4 .2 \\
\hline \multirow[t]{5}{*}{ Other } & Respiration rate & $\begin{array}{l}\text { Increase: Balteș et al. (2011), Salimpoor et al. (2009), Salimpoor et al. (2011) } \\
\text { No effect: Benedek and Kaernbach (2011), Grewe et al. (2011), Mori and Iwanaga (2017), Sumpf et al. } \\
\text { (2015) }\end{array}$ \\
\hline & Respiration depth & $\begin{array}{l}\text { Increase: Benedek and Kaernbach (2011), Blood and Zatorre (2001), Grewe et al. (2009a) } \\
\text { No effect: Mori and Iwanaga (2017) }\end{array}$ \\
\hline & Muscle tension & $\begin{array}{l}\text { Increase: Blood and Zatorre (2001) } \\
\text { No effect: Rickard (2004) }\end{array}$ \\
\hline & Salivary cortisol & $\begin{array}{l}\text { Decrease: Fukui and Toyoshima (2013) } \\
\text { No effect: Rickard (2004) }\end{array}$ \\
\hline & $\begin{array}{l}\text { Lesser-used } \\
\text { measures }\end{array}$ & See Subsection 3.4 .3 \\
\hline
\end{tabular}

Table 3: Physiological correlates of music-evoked chills

increase with increased frequency of MECs (Rickard, 2004). Salivary cortisol levels decreased when listening to music that induces MECs (Fukui \& Toyoshima, 2013) but not with increased frequency of MECs (Rickard, 2004). Other salivary hormone levels showed different patterns, with increases in estradiol, and no changes in testosterone, though it is important to note that this was in response to listening to music self-selected as likely to elicit MECs - occurrence of MECs was not actually recorded in this study (Fukui \& Toyoshima, 2013). Pupil diameter increased during MECs, but this was not the case for eye blinks, saccade amplitude, or saccade dispersion (Laeng et al., 2016), and resting physiological state, recorded as a pre-experiment baseline, was found to be associated with the number of MECs when listening to self-selected music (Mori \& Iwanaga, 2014b).

\subsection{Neural correlates}

The neural correlates of MECs are discussed in many papers, particularly when referring to the results of Blood and Zatorre (2001) and Salimpoor et al. (2011). Some very thorough reviews explore the neuroscience of music and emotion in depth, with significant coverage of the neuroscientific literature on MECs (e.g., Archie et al., 2013; Brattico et al., 2013; Brattico \& Pearce, 2013; Chanda \& Levitin, 2013; Habibi \& Damasio, 2014; Koelsch, 2010, 2014; Salimpoor \& 
Zatorre, 2013; Schaefer, 2017; Zatorre, 2003, 2015; Zatorre \& Salimpoor, 2013). Therefore, this section of our review presents a brief summary of the main findings, examining how MECs are associated with the basal ganglia and other neural structures, as well as results from lesion and neurochemical studies, and research on anhedonia (see Table 4 for a summary by structure).

\subsubsection{Basal ganglia}

Structures belonging to the basal ganglia have been repeatedly linked with MECs. In the dorsal striatum, increases in activation have been found in the putamen and left caudate nucleus when comparing music listening with and without the experience of pleasant MECs (Klepzig et al., 2020). Furthermore, in an earlier study, the right caudate nucleus showed increased activation in anticipation of MECs, as well as a positive relationship between dopamine release and number of MECs (Salimpoor et al., 2011). Effects have also been found in the ventral striatum, which showed increased activation in response to pleasant MECs in a healthy control, but not in a patient with lesions following an extended stroke of the left middle cerebral artery (Grunkina et al., 2017). Activation in the left ventral striatum increased when listening to music that was self-selected to elicit pleasant emotional responses, including MECs, and was positively correlated with ratings of MECs intensity (Blood \& Zatorre, 2001). Within the ventral striatum, the right nucleus accumbens showed increased activation during MECs, and a positive relationship between dopamine release, intensity of MECs, and degree of pleasure (Salimpoor et al., 2011), suggesting an involvement of this structure in processing the hedonic and reinforcing aspects of musical pleasure (Chanda \& Levitin, 2013).

\subsubsection{Other subcortical structures and cortical regions}

In addition to the nucleus accumbens, associations with MECs have been reported for a wide range of limbic and paralimbic structures, such as the amygdala (Griffiths et al., 2004; Grunkina et al., 2017) and the left hippocampus, both of which showed decreased activation as MECs intensity increased (Blood \& Zatorre, 2001), as well as the cingulate cortex (Blood \& Zatorre, 2001), the insular cortex (Blood \& Zatorre, 2001; Griffiths et al., 2004; Grunkina et al., 2017; Klepzig et al., 2020), and the orbitofrontal cortex (Blood \& Zatorre, 2001), which all displayed increased activation with MECs (or an impaired ability to experience MECs for patients with an insular lesion - see Subsection 3.5.3), demonstrating a widespread involvement of the limbic system and associated cortical regions. Other brain structures and cortical regions have also shown increased activation with MECs, such as the primary auditory cortex and the secondary somatosensory cortex (Grunkina et al., 2017), the thalamus (Blood \& Zatorre, 2001; Grunkina et al., 2017; Klepzig et al., 2020), the dorsomedial midbrain, the supplementary motor area, the cerebellum (Blood \& Zatorre, 2001), including the right cerebellar hemisphere (Klepzig et al., 2020), and the locus coeruleus, as indicated by pupillary dilation during MECs (Laeng et al., 
2016), as well as decreased activation for the ventromedial prefrontal cortex, the cuneus, and the precuneus (Blood \& Zatorre, 2001)

\subsubsection{Structural, neuropsychological, and neurochemical findings}

White matter connectivity was investigated by Sachs et al. (2016), who reported increased tract volume from the posterior superior temporal gyrus to the anterior insula and medial prefrontal cortex - these tracts being part of the uncinate fasciculus, among others - in people who experience MECs frequently and consistently, but no difference in corticospinal tract volume, suggesting that these differences are specific, and not a result of general differences in white matter connectivity (Sachs et al., 2016). A study taking advantage of data from the Human Connectome Project (Essen et al., 2013) revealed that proneness to MECs is associated with higher resting-state functional connectivity between the default network and sensory and motor cortices, between the ventral default and salience networks, and lower connectivity between the cerebellum and somatomotor cortex, suggesting a greater integration between environmental perception and internal emotional experience (Williams et al., 2018).

Lesion studies have provided support for the involvement of these structures and tracts. A patient with lesions in the left insula and left amygdala exhibited impaired emotional processing of music, despite normal music perception and processing (Griffiths et al., 2004). Another patient lost the ability to perceive subtle differences between musical performances and to experience pleasure and MECs, following a lesion in the right putamen that impaired connectivity between the right insula and the superior temporal lobe, including the auditory cortex (Satoh et al., 2016). Finally, another patient with damage in the pyramidal tract, uncinate fasciculus, and left anterior insular cortex showed reports of MECs intensity consistent with a healthy control, but diminished bodily responses as indexed by changes in skin conductance level and skin conductance response (Grunkina et al., 2017).

Neurochemical findings provide some clarity on the role of endogenous opioids and dopamine. MECs were attenuated in three out of ten participants administered with naloxone, an opiate receptor antagonist (Goldstein, 1980) - a preliminary finding which received further support from a decrease in self-reported pleasure for pleasurable music after inducing anhedonia with naltrexone, a $\mu-$ opioid antagonist similar to naloxone (Mallik et al., 2017). Furthermore, the amount of time experiencing MECs was higher than placebo following intake of levodopa, a dopamine precursor, and lower than placebo following intake of risperidone, a dopamine antagonist (Ferreri et al., 2019).

\subsubsection{Anhedonia}

The literature on anhedonia further supports the results of neuroimaging, neurochemical, and lesion studies. Higher physical anhedonia, characterised by diminished reward from physical and sensory experiences, has been associated with experiencing MECs less often (Nusbaum et al., 2015), and shown to involve 


\begin{tabular}{|c|c|c|}
\hline Group & Structure & Papers \\
\hline \multirow[t]{4}{*}{ Basal ganglia } & Dorsal striatum: Putamen & $\begin{array}{l}\text { Increased activation: Klepzig et al. (2020) } \\
\text { Impaired with right lesion: Satoh et al. (2016) }\end{array}$ \\
\hline & Dorsal striatum: Caudate nucleus & $\begin{array}{l}\text { Increased left activation: Klepzig et al. (2020) } \\
\text { Increased right activation: Salimpoor et al. (2011) }\end{array}$ \\
\hline & Ventral striatum & $\begin{array}{l}\text { Increased activation: Grunkina et al. (2017) } \\
\text { Increased left activation: Blood and Zatorre (2001) }\end{array}$ \\
\hline & Ventral striatum: Nucleus accumbens & Increased right activation: Salimpoor et al. (2011) \\
\hline \multirow[t]{5}{*}{$\begin{array}{l}\text { Limbic and } \\
\text { paralimbic } \\
\text { structures }\end{array}$} & Amygdala & $\begin{array}{l}\text { Decreased activation: Blood and Zatorre (2001) } \\
\text { Increased activation: Grunkina et al. (2017) } \\
\text { Impaired with left lesion: Griffiths et al. (2004) }\end{array}$ \\
\hline & Hippocampus & Decreased left activation: Blood and Zatorre (2001) \\
\hline & Cingulate cortex & Increased activation: Blood and Zatorre (2001) \\
\hline & Insular cortex & $\begin{array}{l}\text { Increased activation: Blood and Zatorre (2001), Grunkina et al. (2017), } \\
\text { Klepzig et al. (2020) } \\
\text { Impaired with left lesion: Griffiths et al. (2004), Grunkina et al. (2017) }\end{array}$ \\
\hline & Orbitofrontal cortex & Increased activation: Blood and Zatorre (2001) \\
\hline \multirow[t]{9}{*}{ Other } & Primary auditory cortex & Increased activation: Grunkina et al. (2017) \\
\hline & Ventromedial prefrontal cortex & Decreased activation: Blood and Zatorre (2001) \\
\hline & Thalamus & $\begin{array}{l}\text { Increased activation: Blood and Zatorre (2001), Grunkina et al. (2017), } \\
\text { Klepzig et al. (2020) }\end{array}$ \\
\hline & Dorsomedial midbrain & Increased activation: Blood and Zatorre (2001) \\
\hline & Supplementary motor area & Increased activation: Blood and Zatorre (2001) \\
\hline & Cerebellum & $\begin{array}{l}\text { Increased activation: Blood and Zatorre }(2001) \\
\text { Increased right activation: Klepzig et al. }(2020)\end{array}$ \\
\hline & Locus coeruleus & Increased activation: Laeng et al. (2016) \\
\hline & Cuneus & Decreased activation: Blood and Zatorre (2001) \\
\hline & Precuneus & Decreased activation: Blood and Zatorre (2001) \\
\hline \multirow[t]{4}{*}{ Tracts } & Uncinate fasciculus & $\begin{array}{l}\text { Impaired with lesion: Grunkina et al. (2017) } \\
\text { Increased tract volume: Sachs et al. (2016) }\end{array}$ \\
\hline & Pyramidal tract & $\begin{array}{l}\text { Impaired with lesion: Grunkina et al. (2017) } \\
\text { No effect of corticospinal tract volume: Sachs et al. (2016) }\end{array}$ \\
\hline & Right insula to superior temporal lobe & Impaired with lesion: Satoh et al. (2016) \\
\hline & $\begin{array}{l}\text { Default network to sensory and motor } \\
\text { cortices }\end{array}$ & High functional connectivity: Williams et al. (2018) \\
\hline
\end{tabular}

Table 4: Neural correlates of music-evoked chills

reduced activation in the left ventral striatum and increased activation in the ventromedial cortex (Dowd \& Barch, 2012; Harvey et al., 2007; as cited by Nusbaum et al., 2015). Specific musical anhedonia, characterised by a failure to find music rewarding despite normal music perception and the absence of generalised anhedonia, can be measured with the Barcelona Musical Reward Questionnaire (Mas-Herrero et al., 2013), and has been found to be associated with fewer and less intense experiences of MECs, and a lack of increase in skin conductance response, despite behavioural reports of MECs by some anhedonic participants (Mas-Herrero et al., 2014). Interestingly, tract volume between the left superior temporal gyrus and the left nucleus accumbens was shown to be lower for participants with severe musical anhedonia (Loui et al., 2017), providing further support for the involvement of white matter connectivity between auditory and limbic structures. 


\subsection{Elicitors}

The stimulus-driven elicitors of MECs fall into three broad categories: low-level acoustic elicitors, representing basic properties of the auditory signal, high-level musical elicitors, representing stimulus properties more specific to music, such as harmonic movement, and emotional elicitors, representing subjectively felt emotions in pieces of music. Understanding these elicitors is necessary in order to assess which psychological mechanisms might underlie MECs, and to inform theoretical perspectives on the function of MECs (see Section 3.8). As a result, considerable attention has been given to identifying these elicitors, as reviewed in this section, and summarised in Table 5 .

\subsubsection{Acoustic elicitors}

MECs have repeatedly been linked with dynamic acoustic changes, and most often when such changes are sudden (Auricchio, 2017; Guhn et al., 2007; Nagel et al., 2008; Polo, 2017; Sloboda, 1991). More specifically, increased loudness or more frequent peaks in loudness were found around the onset of MECs (Beier et al., 2020; Grewe et al., 2007; Guhn et al., 2007; Honda et al., 2020; Nagel et al., 2008), particularly in the $920-4400 \mathrm{~Hz}$ band (Nagel et al., 2008). Loudness was also associated with continuous ratings of MECs intensity (Bannister \& Eerola, 2018), and experimentally increasing the loudness of a musical passage known to often induce MECs and likely to engage auditory looming (see Subsection 3.8.4) resulted in more frequent experiences of MECs (Bannister, 2020b). Pleasure could be a mediating factor, however, with changes in volume leading to increased pleasure in some cases (Grewe et al., 2007), but decreased in others (Bannister, 2020b). MECs have also been shown to co-occur with higher event density (Bannister \& Eerola, 2018; Nagel et al., 2008; Polo, 2017), expansion of the frequency range in the high or low register (Guhn et al., 2007; Polo, 2017), higher spectral centroid and spectral flux (Bannister \& Eerola, 2018), increased roughness, dissonance, or fluctuation strength (Bannister \& Eerola, 2018; Beier et al., 2020; Grewe et al., 2007; Nagel et al., 2008; Park et al., 2019), higher variance in interaural level difference, a measure which captures rotation in binaural recordings (Honda et al., 2020), and increased sharpness or brightness (Bannister \& Eerola, 2018; Beier et al., 2020; Grewe et al., 2007; Honda et al., 2020), although, for one specific song, increasing brightness was found to reduce the frequency of MECs (Bannister, 2020b).

\subsubsection{Musical elicitors}

A number of features more specific to music have also been identified as potential elicitors of MECs, expanding on what was initially described as "dramatic peaks and valleys in music" (Goldstein, 1980, p. 127). Related to increases in loudness discussed in the previous paragraph, crescendi, build-ups, and climaxes have been linked with MECs (Auricchio, 2017; Bannister, 2020a; Bannister \& Eerola, 2018; Panksepp, 1995; Polo, 2017; Solberg \& Dibben, 2019). In addition to sudden dynamic changes, Sloboda (1991) identified several structural characteristics 
of musical excerpts that elicit MECs, such as new or unprepared harmonies, sudden textural changes, melodic appoggiaturas, enharmonic changes, specific melodic or harmonic sequences, or prominent musical events arriving earlier than prepared for, among others. Similar melodic and harmonic properties, including structural transitions and alterations such as changes in tonality, were subsequently associated with MECs in several empirical studies (Auricchio, 2017; Bannister, 2020a; Bannister \& Eerola, 2018; Guhn et al., 2007; Mlejnek, 2013; Schurtz et al., 2012), in addition to rhythmic properties (Schurtz et al., 2012; Solberg \& Dibben, 2019), although the two latter studies lack specific detail about which rhythmic properties were involved (for a hypothesis about optimal tempo, see McEvilly, 1999). A recurrent theme is textural changes (Auricchio, 2017; Polo, 2017; Sloboda, 1991; Solberg \& Dibben, 2019), particularly with the entrance of new instruments, and the alternation, contrast, or communion between solo and accompanying instruments (Auricchio, 2017; Bannister, 2020a; Bannister \& Eerola, 2018; Goodchild et al., 2019; Guhn et al., 2007; Mlejnek, 2013), which are considered particularly pleasurable by listeners (Grewe et al., 2007). Voice and lyrics have also been identified as potent elicitors of MECs (Bannister, 2020a; Schurtz et al., 2012), and some researchers have identified passages from slow movements (Guhn et al., 2007) and virtuosity (Mlejnek, 2013) as possible causes of MECs.

Finally, in a causal study by Bannister and Eerola (2018), MECs were found to happen less frequently, and to be rated as less intense, when specific passages known to often elicit MECs were removed from three pieces of music. Interestingly, as opposed to MECs, skin conductance response did not diminish when these passages were removed. This suggests that physiological arousal is dependent on local musical context, and possibly linked to the anticipation of MECs. Another point of interest reported by Bannister and Eerola (2018) is that acoustic and musical elicitors might be intrinsically related, since the entrance of new instruments, for instance, would naturally come along with dynamic and spectral changes (see also Auricchio, 2017). Research that comprehensively teases apart the effects of acoustic and musical elicitors is needed to better understand how stimulus properties influence the occurrence of MECs.

\subsubsection{Emotional elicitors}

MECs can also arise from the perception of emotions expressed by music, which, for present purposes, can be broadly grouped into valence, emotionality, and meaning. While frequency of self-reported MECs has been found to increase when listening to music rated as positively valenced (Grewe et al., 2011), associations between MECs and perceived sadness in female participants were found by Panksepp (1995) following a series of experiments. In this study, however, both happy and sad music were reported to elicit MECs, as was the case in other studies linking both positive and negative perceived emotions with MECs (Bannister, 2020a; Mori \& Iwanaga, 2017). Rather than valence, greater perceived emotionality, whether positively or negatively valenced, has often been identified as a possible cause of MECs, whether it is referred to as such (Beier et al., 2020), 
as emotional power (Rickard, 2004), as perceived emotional content (Panksepp, 1995), as emotional intensity (Bannister \& Eerola, 2018), or as the climactic stage of an aesthetic experience (Panzarella, 1980).

Finally, related to the effect of lyrics discussed in the previous subsection (Bannister, 2020a; Schurtz et al., 2012), MECs have been found to be associated with the perception of meaning in music, whether it is meaning of lyrics (Bannister, 2020a), personal meaning (Craig, 2009; Goldstein, 1980), or extra-musical meaning, such as pride or patriotism (Mlejnek, 2013). Notably, some studies of the effects of meaning have focused on priming effects, and resulted in conflicting perspectives. Specifically, while there was little to no effect of presenting various types of priming stimulus (national anthems, stories, architectural objects, paintings) on the frequency or duration of MECs when subsequently listening to a piece of music (Konečni et al., 2007), being exposed to a complex, existential statement, as opposed to an incoherent statement, increased the number of chills experienced when watching subsequent video clips (Schoeller, Eskinazi, \& Garreau, 2018; Schoeller \& Perlovsky, 2016). Interestingly, Konečni et al. (2007) also observed that there was no priming effect of experiencing MECs themselves on subsequent experiences of MECs, whereas frequency of MECs has been found to increase (Benedek \& Kaernbach, 2011) or decrease (Laeng et al., 2016) with trial number during experiments (and therefore, following previous occurrences of MECs), highlighting a lack of consensus on the matter.

\subsubsection{Underlying mechanisms}

When it comes to understanding how these various elicitors might cause MECs, it is useful to consider potential underlying psychological mechanisms. A useful framework for doing so comes from an extensive body of work which sought to provide a unified theory of evoked musical emotions in the form of a set of underlying mechanisms (Juslin, 2013; Juslin \& Västfjäll, 2008), the diversity of which was echoed by Huron (2016) when discussing the range of ways in which sounds are thought to evoke pleasure. It could be that these mechanisms are also involved in the experience of MECs, by evoking emotions which would in turn induce MECs, or by directly inducing MECs, but not fully-fledged emotional experiences (see Subsection 3.2.1).

In this framework, brain stem reflex refers to the process by which low-level acoustic features quickly and automatically elicit emotions when exceeding a threshold value (Juslin, 2013), and would provide a reasonable explanation as to why acoustic elicitors such as sudden changes in loudness or dissonance might cause physiological arousal and MECs (L. Harrison \& Loui, 2014; Juslin et al., 2014), although it is worth pointing out that for MECs, the corresponding mechanism reflects relatively automatic reactions to sudden changes in the acoustic signal, rather than a psychological startle response specifically. Musical expectation benefits from a long-standing theoretical background (Hanslick, 1854; Meyer, 1956), and is based on the hypothesis that developing expectations follows a process of probabilistic learning of the statistical regularities in musical structure (Pearce, 2018; Saffran et al., 1999). In other words, with exposure 


\begin{tabular}{|c|c|c|}
\hline Category & Elicitor & Papers \\
\hline \multirow[t]{7}{*}{ Acoustic } & Loudness & $\begin{array}{l}\text { Sudden change: Auricchio (2017), Guhn et al. (2007), Nagel et al. (2008), Polo (2017), } \\
\text { Sloboda (1991) } \\
\text { Increase or more frequent peaks: Bannister and Eerola (2018), Bannister (2020b), Beier } \\
\text { et al. (2020), Grewe et al. (2007), Guhn et al. (2007), Honda et al. (2020), Nagel et al. (2008) }\end{array}$ \\
\hline & Event density & High levels: Bannister and Eerola (2018), Nagel et al. (2008), Polo (2017) \\
\hline & Frequency range & Expansion in high or low register: Guhn et al. (2007), Polo (2017) \\
\hline & Spectral centroid or flux & High levels: Bannister and Eerola (2018) \\
\hline & $\begin{array}{l}\text { Roughness, dissonance, or } \\
\text { fluctuation strength }\end{array}$ & $\begin{array}{l}\text { Increase: Bannister and Eerola (2018), Beier et al. (2020), Grewe et al. (2007), Nagel et al. } \\
\text { (2008), Park et al. (2019) }\end{array}$ \\
\hline & Brightness or sharpness & $\begin{array}{l}\text { Increase: Bannister and Eerola (2018), Beier et al. (2020), Grewe et al. (2007), Honda et al. } \\
(2020) \\
\text { Decrease: Bannister (2020b) }\end{array}$ \\
\hline & Interaural level difference & High variance: Honda et al. (2020) \\
\hline \multirow[t]{6}{*}{ Musical } & $\begin{array}{l}\text { Crescendi, build-ups, and } \\
\text { climaxes }\end{array}$ & $\begin{array}{l}\text { Auricchio (2017), Bannister and Eerola (2018), Bannister (2020a), Goldstein (1980), } \\
\text { Panksepp (1995), Polo (2017), Solberg and Dibben (2019) }\end{array}$ \\
\hline & $\begin{array}{l}\text { Changes in structure, melody, } \\
\text { or harmony }\end{array}$ & $\begin{array}{l}\text { Auricchio (2017), Bannister and Eerola (2018), Bannister (2020a), Guhn et al. (2007), } \\
\text { Mlejnek (2013), Schurtz et al. (2012), Sloboda (1991) }\end{array}$ \\
\hline & Textural changes & $\begin{array}{l}\text { In general: Auricchio (2017), Polo (2017), Sloboda (1991), Solberg and Dibben (2019) } \\
\text { Entrance or interplay between instruments: Auricchio (2017), Bannister and Eerola } \\
\text { (2018), Bannister (2020a), Goodchild et al. (2019), Guhn et al. (2007), Mlejnek (2013) }\end{array}$ \\
\hline & Voice and lyrics & Bannister (2020a), Schurtz et al. (2012) \\
\hline & Slow movements & Guhn et al. (2007) \\
\hline & Virtuosity & Mlejnek (2013) \\
\hline \multirow[t]{3}{*}{ Emotional } & Perceived valence & $\begin{array}{l}\text { Positive: Grewe et al. (2011) } \\
\text { Both positive and negative: Bannister (2020a), Mori and Iwanaga (2017), Panksepp } \\
(1995)\end{array}$ \\
\hline & Perceived emotionality & $\begin{array}{l}\text { Bannister and Eerola (2018), Beier et al. (2020), Grewe et al. (2009a), Panksepp (1995), } \\
\text { Panzarella (1980), Rickard (2004) }\end{array}$ \\
\hline & Perceived meaning & $\begin{array}{l}\text { Effect: Bannister (2020a), Craig (2009), Goldstein (1980), Mlejnek (2013), Schoeller and } \\
\text { Perlovsky (2016), Schoeller, Eskinazi, and Garreau (2018) } \\
\text { No effect: Konečni et al. (2007) }\end{array}$ \\
\hline
\end{tabular}

Table 5: Elicitors of music-evoked chills

to a musical culture, listeners automatically and implicitly develop an internal model of the structure of a musical style through a process called statistical learning, which is then used, when listening to music, to form expectations about the possible continuations of the music through a process called probabilistic prediction (Pearce, 2018). These learned expectations can be violated, delayed, or confirmed, resulting in induced emotional and aesthetic responses (Cheung et al., 2019; Gold et al., 2019; Huron, 2006; Juslin, 2013; Steinbeis et al., 2006), presumably in order to drive learning to improve future predictions (Pearce, 2018). Musical expectation has often been posited as a cause of MECs (L. Harrison \& Loui, 2014; Huron, 2006; Huron \& Margulis, 2010; Juslin, 2013; Juslin \& Västfjäll, 2008; McDermott, 2012; Mencke et al., 2019; Pearce \& Wiggins, 2012; Salimpoor et al., 2011; Sloboda, 1991), and indeed, the majority of the musical elicitors discussed in this section could engage such a mechanism. Interestingly, Levinson (2006) suggested that there might be two types of MECs, the first type induced timbrally or dynamically, and the second type induced melodically, harmonically, or rhythmically. This is consistent with the possible involvement of brain stem reflex, on the one hand, and musical expectation, on the other. 
Other mechanisms underlying emotional responses to music have also been discussed in relationship to MECs, such as episodic memory (Goldstein, 1980), evaluative conditioning, or emotional contagion (L. Harrison \& Loui, 2014), all of which have been linked speculatively by these authors to some of the emotional elicitors discussed in the previous subsection. Paradoxically, when underlying mechanisms were explicitly investigated, either systematically (Juslin et al., 2014) or through self-reports (Bannister, 2020a; Bannister \& Eerola, 2018), emotional contagion was strongly linked to MECs, but brain stem reflex and musical expectation were not. These results, however, could reflect the distinct possibility that the experimental manipulations of the musical stimuli did not adequately target the mechanisms in question, that listeners do not have sufficient conscious access to the reasons why they experience MECs to be able to self-report them, or that such conscious access varies between mechanisms. Further investigation is therefore needed to obtain conclusive answers about the psychological mechanisms that underlie MECs.

\subsubsection{Associated factors}

There exist other factors that potentially contribute to the elicitation of MECs. While these have rarely been the primary topic of investigation, they are often reported, and provide useful context to the findings discussed in this section. Some authors covered listening situations, comparing occurrences of MECs when listening to music alone or with others. In most cases, no differences were found (Egermann et al., 2011; Nusbaum et al., 2014; Sutherland et al., 2009), although peaks in skin conductance response were higher during MECs when listening alone than when listening in a group (Egermann et al., 2011), and survey respondents reported most experiences of MECs to happen during solo listening (Bannister, 2020a). These findings might reflect an effect of attention (Beier et al., 2020; Nusbaum et al., 2014; see also Mori \& Iwanaga, 2014a), possibly related to alcohol intake being found to reduce frequency of MECs (Starcke et al., 2019), which would provide further support for the suggested role of attention in aesthetic responses (see Subsection 3.2.3). Interestingly, theories of dynamic attending (Jones \& Boltz, 1989; Large \& Jones, 1999) suggest a relationship between attention and temporal expectation, through which attention is directed at points in time which are expected to be more salient. Such a relationship could provide a possible mechanism through which increased attention affects MECs via musical expectation (see Subsection 3.6.4), and could provide a partial explanation for the involvement of neural structures associated with predictive timing and rhythm perception in MECs (Grahn \& Brett, 2007; Teki et al., 2011), such as the basal ganglia (see Subsection 3.5.1). Future research should aim to investigate these issues in order to establish the precise nature of the relationship between attention and MECs.

Another important effect is that of repetition and familiarity. Listening to the same piece of music several times within a single experimental session was not found to affect the frequency or intensity of MECs (Balteș et al., 2011; Bannister, 2020b; Blood \& Zatorre, 2001), but doing so every day over a week led to reduced 
frequency of MECs (Grewe et al., 2007), possibly due to habituation, although this longitudinal effect was investigated in only one participant. Over longer time scales, MECs have been reported to be a reliable response, and even to grow with repeated listening (Sloboda, 1991). More generally, conflicting effects of familiarity have been identified, with some studies reporting more occurrences of MECs for familiar stimuli (Craig, 2005; Grewe et al., 2009a; Panksepp, 1995; Rickard, 2004; Weth et al., 2015), and other studies reporting no effects of stimulus familiarity (Bannister, 2019; Bannister \& Eerola, 2018; Benedek \& Kaernbach, 2011; Colver \& El-Alayli, 2016; Guhn et al., 2007; Rickard, 2004; Wassiliwizky et al., 2015), although some of these studies featured stimuli which were either all very familiar (Benedek \& Kaernbach, 2011), or very unfamiliar (Colver \& El-Alayli, 2016; Guhn et al., 2007). Familiarity has been argued to be a strong driver of aesthetic experiences, in conjunction with surprise, complexity, and expectation (Greasley \& Lamont, 2016; Salimpoor et al., 2015; Verhaeghen, 2018), and could contribute to the elicitation of MECs by increasing recognition of meaning in music (see Subsection 3.6.3) or by promoting a conflict between schematic and veridical expectation (Bharucha, 1994; Huron, 2006; Miranda \& Ullman, 2007; Salimpoor et al., 2015), allowing unconscious surprise, caused by schematically unexpected events, to continue to occur in very familiar music, which would be veridically highly expected. This remains speculative, until further empirical research provides greater clarity on the association between familiarity and MECs.

\subsection{Individual differences}

While most people seem to have the ability to experience MECs (see Subsection 3.1.3), not everyone can or does so equally often. As a result, there has been some interest in identifying how individual differences might affect the prevalence of MECs and the frequency of experiencing them. In this section, we review the evidence on the role played by gender, age, musical training, and personality differences in the experience of MECs (see summary in Table 6).

\subsubsection{Gender, age, and musical training}

Panksepp (1995) identified in a series of experiments that women find sad music more likely to cause MECs than men, and vice versa for happy music, among other findings showing, especially for women, a relationship between MECs and perceived sadness. Similarly, Benedek and Kaernbach (2011) detected an effect of gender, with more women experiencing piloerection than men when listening to music and film audio, although the study involved an uneven gender ratio. The vast majority of studies that analysed the effect of gender, however, have reported no influence on MECs (see Table 6). The effect of age on MECs is less clear. Correlations with age have been found (Williams et al., 2018), including for some (e.g., goose pimples) but not all (e.g., shivers down the spine) reactions to music related to MECs (Mlejnek, 2013), and age positively predicted a small amount of variance in the number of MECs experienced during an opera performance 
(Balteș \& Miu, 2014), whereas no effect of age was identified by Grewe et al. (2009a), Mori and Iwanaga (2014b), Starcke et al. (2019), and Zickfeld, Schubert, Seibt, Blomster, et al. (2019). Regarding effects of musical training, Nusbaum and Silvia (2011) found that playing an instrument is a significant predictor of the frequency of experiences of MECs, while Beier et al. (2020) reported effects of Western music theory knowledge on MECs experienced when listening to Western, Indian, but not Chinese music. However, other empirical evidence does not support an effect of musical training or musical sophistication (Müllensiefen et al., 2014) on MECs (Bannister \& Eerola, 2018; Grewe et al., 2009a; Guhn et al., 2007; Polo, 2017; Rickard, 2004). It is important to note that most of these findings were not hypothesis-driven and there is very little theoretical basis for hypothesising effects of gender, age and musical training on MECs. Considering this limitation, as well as the limited scope of some of the results (discussed above), it is reasonable to assume that, for the most part, MECs are experienced independently of gender, age, and musical training.

\subsubsection{Personality correlates}

By far the most documented personality correlate of the experience of MECs is openness to experience - a Big Five personality trait characteristic of individuals who are curious, innovative, imaginative, sensitive to the arts, and who experience a wide range of feelings and emotions (McCrae, 2007). The relationship between MECs and openness to experience has been identified in many studies (see Table 6), though it was ambiguous in some cases (Mori \& Iwanaga, 2015; Sumpf et al., 2015), and not present in others (Mathis \& Han, 2017; Rickard, 2004; Starcke et al., 2019). Importantly, the NEO Personality Inventory and the NEO Five-Factor Inventory (Costa \& McCrae, 1992) used in the majority of these studies both include an item about experiencing chills, which counts towards openness to experience. This raises the concern that the empirical relationship between MECs and openness to experience might be driven by the contribution of this item towards the scale. However, this seems not to be the case, because the item about chills is highly correlated with the sum of the remaining items on the openness to experience scale, as shown by corrected item-total correlations for this trait. Moreover, this analysis revealed that out of all items, the one about chills is the most highly correlated with the rest of the scale, making it the best cross-cultural indicator of openness to experience (McCrae, 2007). In addition, this item was confirmed to be related to the number of MECs experienced in a lab environment (Colver \& El-Alayli, 2016). The other Big Five traits have also been investigated, and found to predict some of the variance in the frequency of experiencing MECs when taken together (Nusbaum \& Silvia, 2011; Silvia \& Nusbaum, 2011), and individually in the case of extraversion, neuroticism, and agreeableness (see Table 6), though the relationship for the latter has been found to be both positive (Sumpf et al., 2015; Williams et al., 2018) and negative (Maruskin et al., 2012). Agreeable individuals were also found to be more likely

to experience MECs with piloerection rather than without (Sumpf et al., 2015).

Aside from the Big Five traits, many personality factors have been investi- 


\begin{tabular}{|c|c|c|}
\hline Type & Characteristic & Papers \\
\hline \multirow[t]{2}{*}{ Demographic } & Gender & $\begin{array}{l}\text { Effect: Benedek and Kaernbach (2011), Panksepp (1995) } \\
\text { No effect: Bannister (2019), Grewe et al. (2007), Grewe et al. (2009a), Guhn et al. (2007), } \\
\text { Goldstein (1980), N. R. Harrison and Clark (2016), Mlejnek (2013), Mori and Iwanaga } \\
\text { (2014b), Polo (2017), Rickard (2004), Silvia and Nusbaum (2011), Starcke et al. (2019), } \\
\text { Sutherland et al. (2009), Williams et al. (2018), Zickfeld, Schubert, Seibt, Blomster, et al. } \\
\text { (2019) }\end{array}$ \\
\hline & Age & $\begin{array}{l}\text { Effect: Balteș and Miu (2014), Mlejnek (2013), Williams et al. (2018) } \\
\text { No effect: Grewe et al. (2009a), Mori and Iwanaga (2014b), Starcke et al. (2019), Zickfeld, } \\
\text { Schubert, Seibt, Blomster, et al. (2019) }\end{array}$ \\
\hline Experiential & Musical training & $\begin{array}{l}\text { Effect: Beier et al. (2020), Nusbaum and Silvia (2011) } \\
\text { No effect: Bannister and Eerola (2018), Grewe et al. (2009a), Guhn et al. (2007), Polo } \\
\text { (2017), Rickard (2004) }\end{array}$ \\
\hline \multirow[t]{6}{*}{ Personality } & Big Five & Effect: Nusbaum and Silvia (2011), Silvia and Nusbaum (2011) \\
\hline & Big Five: Openness & $\begin{array}{l}\text { Effect: Bannister (2020a), Colver and El-Alayli (2016), Maruskin et al. (2012), McCrae } \\
\text { (2007), Mori and Iwanaga (2015), Nusbaum and Silvia (2011), Silvia and Nusbaum (2011), } \\
\text { Silvia et al. (2015), Sumpf et al. (2015) } \\
\text { Ambiguous: Mori and Iwanaga (2015), Sumpf et al. (2015) } \\
\text { No effect: Mathis and Han (2017), Rickard (2004), Starcke et al. (2019) }\end{array}$ \\
\hline & Big Five: Extraversion & Effect: Maruskin et al. (2012), Rickard (2004), Sumpf et al. (2015), Williams et al. (2018) \\
\hline & Big Five: Neuroticism & Effect: Maruskin et al. (2012), Silvia et al. (2015), Sumpf et al. (2015), Williams et al. (2018) \\
\hline & Big Five: Agreeableness & $\begin{array}{l}\text { Positive effect: Sumpf et al. (2015), Williams et al. (2018) } \\
\text { Negative effect: Maruskin et al. (2012) }\end{array}$ \\
\hline & Lesser-used characteristics & See Subsection 3.7 .2 \\
\hline
\end{tabular}

Table 6: Individual differences in susceptibility to music-evoked chills

gated. Experiencing MECs was found to be associated with being more observing and judging (N. R. Harrison \& Clark, 2016), less susceptible to anger (Laeng et al., 2016), more likely to follow the music-empathising cognitive style of music listening, which is linked with a greater focus on emotional content (Linnemann et al., 2018), and more likely to listen to music in order to reduce negative affect rather than to stimulate fun (Starcke et al., 2019). There are conflicting results about the effects of reward dependence and sensitivity (Bannister, 2020b; Grewe et al., 2007; Mori \& Iwanaga, 2015, see Subsection 3.5.4 for the relationship between MECs and anhedonia), thrill and adventure seeking (Grewe et al., 2007; Mathis \& Han, 2017), stylistic preference (Bannister \& Eerola, 2018; Nusbaum \& Silvia, 2011), and aesthetic fluency, a measure of expertise in the arts (N. R. Harrison \& Clark, 2016; Silvia \& Nusbaum, 2011), and no effects were detected for fluid intelligence (Silvia \& Nusbaum, 2011), mood (Balteș \& Miu, 2014), vividness of visual imagery (Balteș \& Miu, 2014), or impulsive or anxious behaviour (Honda et al., 2020).

Interestingly, when distinguishing between different categories of chills (see Subsection 3.1.4), personality correlates differ. Goosetingles have been associated with extraversion, approach temperament, and positive emotionality, while coldshivers have been linked with neuroticism, avoidance temperament, and negative emotionality (Maruskin et al., 2012). Similarly, while there appears to be no effect of trait empathy on MECs as a single construct (Balteș \& Miu, 2014; Bannister, 2020b), empathy has been found to be associated with moving chills, but not cold or warm chills (Bannister, 2019), echoing the results of a meta-analysis in which trait empathic concern, associated with the state of being moved, has been linked to chills (Zickfeld et al., 2017). 


\subsection{Theoretical perspectives on function}

The evidence reviewed so far mostly addresses what MECs are, and how they are elicited, but there remains the broader question of why MECs occur. This final section surveys current theoretical perspectives about their origin. Most of these perspectives are expressed in terms of the evolutionary basis of chills and they tend to overlap partially to varying degrees while also generally possessing distinctive features. It is therefore important in the context of this review to clearly and carefully delineate these theoretical perspectives on the function of MECs. All of the theories are speculative to some degree. It is because of their speculative nature that we are closing rather than opening this review with these. At this point in time, none of the theoretical perspectives reviewed below have sufficient experimental support to provide a robust platform for scaffolding and interpreting the empirical literature as a whole. However, having surveyed the existing empirical literature, there is value in considering the extent to which empirical results to date corroborate or refute the predictions of these theories and the experimental evidence required for more conclusive assessment. With these goals in mind, we evaluate in this section theories proposing that chills are associated with separation calls, the emotional state of being moved, peak arousal, contrastive valence, and knowledge instinct.

\subsubsection{Separation call}

The idea behind the separation call theory is that, in many animal species, separation calls are used to motivate parents to locate their offspring who might have become lost. According to the theory, this need for social reunion is driven by a feeling of coldness elicited by separation calls and leading to piloerection, potentially caused by an overlap between brain functions governing thermoregulation and social bonding, thereby providing an evolutionary explanation for the purpose of MECs (Panksepp, 1995, 2009; Panksepp \& Bernatzky, 2002). This theory was proposed following early findings suggesting that MECs are more likely in women, with music that is familiar, perceived as sad, and includes high-pitched crescendi, which could be respectively accounted for by mothers being more susceptible to separation calls, by social attachment being a learned behaviour in mammals, by sadness due to potential loss providing the emotional context for potential reunion, and by the acoustic characteristics of separation calls, according to Panksepp (1995). As discussed earlier in this review, however, the effects of gender (see Subsection 3.7.1), familiarity (see Subsection 3.6.5), and stimulus valence (see Subsection 3.6.3) are far from clear-cut, and the diversity in possible elicitors of MECs cannot be fully explained by a similarity with separation calls (see Subsections 3.6.1 and 3.6.2).

Some researchers have argued that chills are indeed related to closeness and social bonding (Bériachvili, 2016; Bicknell, 2007; Maruskin et al., 2012; Schoeller \& Eskinazi, 2019), linked to physiological changes consistent with a state of sadness (Benedek \& Kaernbach, 2011), and that there might be an overlap between thermoregulatory and social functions (for a brief review, see Bannister, 
2019). However, critics of the separation call theory have argued that it fails to account for the possible existence of different types of chills (Levinson, 2006; see also Bannister, 2019; Maruskin et al., 2012) or for chills being experienced in response to a varied range of stimuli (Bériachvili, 2016; Sachs et al., 2018), that it is not consistent with the personality correlates of individuals most susceptible to experiencing MECs (McCrae, 2007), that there is a lack of clarity about which stimulus properties would reflect separation calls (Bannister, 2020a), and that there is no evidence for the occurrence of chills in response to separation calls in nonhuman primates (Altenmüller et al., 2013). Despite an attempt to provide causal support (briefly described in Panksepp \& Bernatzky, 2002, pp. 143-144) for the separation call theory, it does not fully account for current findings in the literature, and a clearer consensus for its supporting evidence would be needed to consider this theoretical perspective even as a partial, if not complete, explanation for the occurrence of MECs.

\subsubsection{Being moved}

Other theoretical perspectives on the function of MECs have proposed that they are related to the emotional state of being moved. Originating in an identified relationship between moving music and MECs (Goldstein, 1980; Panksepp, 1995; Panksepp \& Bernatzky, 2002), the concept found itself included in the aesthetic trinity of Konečni (2005), which comprises awe, being moved, and chills. Within the framework of the aesthetic trinity theory, being moved is often accompanied by chills, although both responses can occur independently, and the rarer response, awe, is always accompanied by experiences of being moved and chills (Konečni, 2005, 2007, 2008, 2013; Konečni et al., 2007). There is empirical support for a relationship between awe and chills (Cotter et al., 2018; Ji et al., 2019; Maruskin et al., 2012; Quesnel \& Riecke, 2018; Schurtz et al., 2012; Silvia et al., 2015), but despite claims that experiencing aesthetic awe results from an evolutionary process of sexual selection (Konečni, 2005), the theory fails to clearly outline mechanisms for the occurrence of MECs (Bériachvili, 2016; Branković, 2013).

In another line of research, being moved has been included in the construct named kama muta, which represents a positive feeling, often involving tears, chills, and a subjective feeling of warmth in the chest, as a result of experiencing or observing an increase in communal sharing or closeness, and is associated with trait empathic concern (Fiske et al., 2019; T. W. Schubert et al., 2018; Seibt et al., 2018; Zickfeld, Schubert, Seibt, Blomster, et al., 2019; Zickfeld et al., 2017, 2019). While the experience of kama muta is not restricted to music listening, the co-occurrence of MECs and tears, notably, is well documented in the music psychology literature (Bannister, 2019; Cotter et al., 2018; Mori \& Iwanaga, 2017; Scherer et al., 2001; Strick et al., 2015).

More generally, there have been many theoretical (e.g., Menninghaus et al., 2015) and empirical (Bannister, 2019, 2020a; Bannister \& Eerola, 2018; Benedek

\& Kaernbach, 2011; Eerola et al., 2016; Panksepp, 1995; Seibt et al., 2017; Strick et al., 2015; Vuoskoski \& Eerola, 2017; Wassiliwizky, Jacobsen, et al., 2017; 
Wassiliwizky, Koelsch, et al., 2017; Wassiliwizky et al., 2015; Weth et al., 2015) associations between MECs and being moved, with additional links to liking and perceived sadness. The aesthetic trinity and kama muta frameworks do not propose fully-fledged mechanisms explaining the relationship between being moved and chills, and furthermore, there is little detail about the evolutionary mechanisms which could underlie that relationship. However, the extent of the discourse is such that it seems appropriate to include the emotional state of being moved in this section, and fleshing it out in more detail should be considered as a promising avenue for future research.

\subsubsection{Peak arousal}

Motivated by a series of empirical findings (Grewe et al., 2009a; Grewe et al., 2007; Guhn et al., 2007; Rickard, 2004; as cited by Benedek \& Kaernbach, 2011), the peak arousal hypothesis was proposed, advancing that MECs occur when a threshold in emotional and physiological arousal is exceeded (Benedek \& Kaernbach, 2011). A closely related idea was first formulated by Blood and Zatorre (2001), who suggested that MECs can be experienced once a certain level of pleasure and emotional arousal is reached, and indeed, many empirical studies have subsequently used MECs as an indicator of pleasurable responses to music, and uncovered relationships between pleasure, subjective arousal, and MECs (see Subsections 3.2.2 and 4.1.4).

Similarly, MECs have been shown unequivocally to be associated with physiological arousal (see Section 3.4), but this theoretical perspective posits more specifically that MECs are indicators of peak emotional and physiological arousal. While some studies have investigated the time-course of such peak responses, there is a lack of agreement about their specific timing with respect to the onset of MECs (see Subsection 3.4.1). Furthermore, little is known about whether or not peaks of arousal or pleasure can occur in the absence of MECs, which raises the question of whether MECs are a cause or a consequence of emotional and physiological arousal. In their study, Benedek and Kaernbach (2011) found some evidence consistent with the peak arousal hypothesis, but also suggested that rapid, shallow breathing during chills is required to further support the hypothesis. Such breathing patterns were not observed in their study, or in most studies of respiration rate and depth during experiences of MECs (see Subsections 3.4.3 and 4.1.4). Overall, the empirical data available to date do not clearly support or refute the peak arousal hypothesis, and further systematic study is needed in order to fully examine the time-course of emotional and physiological arousal, as well as pleasure, in the presence and absence of MECs.

\subsubsection{Contrastive valence}

It has also been proposed that MECs can be caused by musical expectations, most notably through a process called contrastive valence. This process relies on ITPRA, a theory of expectation proposed by Huron (2006), according to which responses to a situation are separated into imagination and tension, its pre- 
outcome components, and prediction, reaction, and appraisal, its post-outcome components. When listening to music, MECs are thought to occur when a rapid, unconscious fear response due to an unexpected outcome causes piloerection, which is subsequently followed by a neutral or positive conscious appraisal of musical sounds as a safe stimulus, leading to pleasure due to the positive contrast in valence between these two responses (Huron, 2006; Huron \& Margulis, 2010). According to the theory, pleasurable chills in response to an unexpected outcome, musical or not, reflect an exaptation of vestigial thermoregulation and intimidation responses, drawing their adaptive value from promoting attention and information processing, rewarding and reinforcing learning when faced with inaccurate predictions, facilitating memory formation, and driving curiosity to detect new, surprising patterns, through the recruitment of the dopaminergic reward system (see Section 3.5), in order to promote more effective decision making, thereby leading to positive future outcomes (Altenmüller et al., 2013; Cantor, 2019; Grewe et al., 2007; Huron, 2006; Huron \& Margulis, 2010; Maruskin et al., 2012; Wassiliwizky, Koelsch, et al., 2017). Although, following Huron (2006), we focus here on contrastive valence, we believe this causal explanation for MECs is potentially also compatible with other theoretical perspectives on the psychological mechanisms underlying the effects of expectation on emotion and pleasure, including theories invoking tension and resolution (Meyer, 1956), and learning progress (Gold et al., 2019).

As discussed previously, many empirical findings are consistent with a role of schematic and veridical expectation in the experience of MECs (see Subsections 3.6.2, 3.6.4, and 3.6.5). There are also distinct subjective, physiological, and neural differences between pre-outcome and post-outcome reactions when experiencing MECs (Bannister \& Eerola, 2018; Grewe et al., 2009a; Salimpoor et al., 2011; Wassiliwizky, Koelsch, et al., 2017), but these findings lack the temporal precision to fully support the exact time-course proposed by the ITPRA theory. In addition, while the relationship between expectation and pleasure has been explicitly investigated (Cheung et al., 2019; Gold et al., 2019), comparable studies have yet to be conducted on the relationship between expectation and MECs. Critics of the theory argue that the lack of a universal stimulus-response pattern for MECs renders fear unlikely to be the primary evolutionary cause of MECs (Bannister, 2020a; Grewe et al., 2007; Nagel et al., 2008). However, this fails to account for the fact that different individuals can experience fear in response to different stimuli, based on experience and circumstances. Moreover, if expectation is involved, we would expect to see individual differences due to stylistic enculturation (Pearce, 2018; and for partial support of an effect of stylistic knowledge, see Beier et al., 2020). As with the other theoretical perspectives reviewed so far, however, contrastive valence doesn't fully account for the experience of MECs, notably by failing to provide an explanation for MECs caused by the emotional expressiveness of music (Levinson, 2006) and emotional elicitors (see Subsection 3.6.3).

Related to a fear-based response due to expectation mechanisms, it has recently been proposed that auditory looming is a possible cause of MECs, presumably reflecting an adaptive need to perceive and signal an approaching 
threat (Bannister, 2019, 2020b; Bannister \& Eerola, 2018). This theoretical perspective, linked to the role of vigilance in expectation (Huron, 2006), could explain how crescendi and sudden increases in loudness might cause MECs (see Subsections 3.6.1 and 3.6.2), and has received recent support from an experiment showing that manipulating loudness affects the occurrence of MECs (Bannister, 2020b). However, the auditory looming theory does not naturally explain the pleasure often associated with MECs, and it remains to be determined whether or not this can be attributed to contrastive valence.

\subsubsection{Knowledge instinct}

According to the knowledge instinct theory (see Schoeller, Perlovsky, \& Arseniev, 2018), humans are driven to learn by modifying mental representations in order to match patterns in perceived stimuli. Knowledge acquisition consists of the creation and improvement of these representations, and knowledge instinct is the fundamental motivation for knowledge acquisition. Emotions arise from satisfaction or dissatisfaction of knowledge instinct, or in other words, from the congruence or incongruence between bottom-up sensory signals and top-down mental models. Positive aesthetic emotions occur when congruence remains high, and when content at the top of the cognitive hierarchy is engaged, possibly resulting in chills and experiences of the sublime (Schoeller, Eskinazi, \& Garreau, 2018; Schoeller \& Perlovsky, 2016; Schoeller, Perlovsky, \& Arseniev, 2018). In other words, chills can occur if stimuli that are relevant to important abstract concepts, such as meaning, are accurately predicted and understood. This theoretical perspective has also been expressed in terms of an interaction between environment and encoded schema (Pelowski et al., 2018; Pelowski et al., 2017).

While this theory could account for the relationship between MECs and the perception of meaning (see Subsection 3.6.3), and has received tentative support from the effect of the coherence of a priming statement on subsequent experiences of chills when watching video clips (Schoeller, 2015; Schoeller, Eskinazi, \& Garreau, 2018; Schoeller \& Perlovsky, 2016), empirical corroboration remains limited due to a relative lack of diversity in the supporting evidence and the difficulty of deriving specific predictions from the theory about the precise timing of chills. Furthermore, the theory is ambiguous about whether chills occur when learning is required or when it is unnecessary (Pelowski et al., 2018), therefore making it unclear how to reconcile the theory with findings showing that MECs occur in response to unexpected musical events (see Subsection 3.6.2).

\section{Discussion}

We have conducted a systematic and critical review of the current literature on MECs, with the purpose of establishing a solid basis for future research. In this discussion, we first summarise each category of findings presented above, before integrating these findings in order to address the questions raised in the introduction. We then provide a preliminary model of MECs and introduce a 
dataset listing pieces of music reported to elicit MECs in the reviewed literature. Finally, we outline a set of open issues, hypotheses, and recommendations for future research.

\subsection{Summary of findings}

\subsubsection{Context}

Most of the empirical work reviewed in Section 3.1 relies on the analysis of self-reports, and on a certain degree of subjective input from the researchers when it comes to interpreting and naming overarching categories and underlying factors. Taken together, however, these results suggest that, while MECs are a complex psychological construct, most of the population experiences them regularly, although not necessarily very frequently. MECs might comprise several psychologically distinct phenomena, are thought to be related to emotional and aesthetic experiences, and to involve a bodily sensation, which most often originates in the head, neck, back, or arms, and can include piloerection. Establishing a clear and consistent conceptual understanding of what exactly is being studied when researching MECs is a critical issue, and Section 3.1 provides a necessary first step in building such a framework.

\subsubsection{Emotion and aesthetics}

The relationship between MECs, emotions, and aesthetics is complex. The purpose of Section 3.2 was not to provide a comprehensive review of the literature on emotion and aesthetics, but rather to situate MECs within well-established frameworks of aesthetic and emotional responses to music, which are widelythough not always universally - accepted. From the evidence reviewed in that section, we conclude that MECs are a pleasurable psychophysiological response to music, and a possible, though not essential, component of emotional and aesthetic experiences of music. This makes them unsuitable as the sole indicator of such experiences, but if used in conjunction with self-reports, they provide attractive properties from an experimental point of view, because they are pleasurable, widespread, stable, memorable, discrete, and when accompanied by piloerection, objectively observable (Brattico \& Pearce, 2013; Brattico \& Varankaitè, 2019; Grewe et al., 2009b; McDermott, 2012; Sloboda, 1991; Stark et al., 2018; Vuust \& Kringelbach, 2010; Zatorre, 2003).

\subsubsection{Measures and paradigms}

In Section 3.3, we found that self-reports and objective measures both provide distinct advantages, but also have their drawbacks. With self-report measures arise the issue of demand characteristics, through which the behaviour of participants can be influenced by the information they can infer about the experimental hypothesis (Juslin, 2016; Orne, 1962). Moreover, self-report measures are also

subject to self-presentation biases and limited awareness of felt emotions, and providing them continuously or retrospectively can respectively cause issues with 
distraction or reliability (Zentner \& Eerola, 2010). These problems do not arise with objective measures, but in the case of research on MECs, such measures are currently limited to the detection of piloerection, which does not encompass the entirety of the experience of MECs (see Subsection 3.1.2), potentially leading to increased type II error rates. Many studies have combined methodologies, thereby combining the complementary advantages of subjective and objective measures, and we advocate this approach in future research. In terms of paradigms, causal approaches have gained traction. They are crucial if we are to gain a better understanding of the causes of MECs, and should be used whenever possible in future research, along with naturalistic listening experiences to increase ecological validity (see Chabin et al., 2020; Eerola, 2018; Hargreaves \& North, 2010; Hodges, 2016), longitudinal designs to study how experiences of MECs change over time (see Greasley \& Lamont, 2016), and cross-cultural approaches to avoid an overrepresentation of classical music and Western participants, as is currently the case in research on MECs (see L. Harrison \& Loui, 2014).

\subsubsection{Physiological correlates}

In Section 3.4, we found that MECs are associated with many physiological changes, and most often with increases in skin conductance response, heart rate, and respiration rate. However, for more ambiguous findings, the quality of the reviewed evidence must also be taken into account (Koelsch \& Jäncke, 2015). Some studies systematically compared physiological responses in the presence or absence of MECs (e.g., Benedek \& Kaernbach, 2011; Craig, 2005; Grewe et al., 2011; Grewe et al., 2009a; Guhn et al., 2007; Mas-Herrero et al., 2014; Mori \& Iwanaga, 2017; Salimpoor et al., 2009; Sumpf et al., 2015), while other studies were correlational in nature, or compared averaged responses at the song level rather than continuous responses at precise moments in time (e.g., Balteș et al., 2011; Carr \& Rickard, 2016; Jaimovich et al., 2013; Rickard, 2004; Salimpoor et al., 2011; Schäfer \& Sedlmeier, 2011). Due to these differences in experimental design, greater weight should be given to findings about the presence of effects for skin conductance level and heart rate, and the absence of an effect for respiration rate. However, these studies are still limited by a lack of replication using different methodological approaches.

More generally, the reviewed evidence is consistent with increases in selfreported arousal when experiencing MECs (Balteș et al., 2011; Carr \& Rickard, 2016; Grewe et al., 2009a; Mori \& Iwanaga, 2015, 2017; Sumpf et al., 2015). However, the time course of physiological responses associated with MECs remains unclear, with changes in physiological arousal either preceding, cooccurring with, or following MECs, making it difficult to assess whether arousal is a cause or a consequence of MECs, or simply a co-occurring phenomenon (see Subsection 3.8.3). Physiological measures are sometimes thought to be relatively non-specific, and only indicative of a general state of arousal (Larsen et al., 2008; Panksepp \& Bernatzky, 2002), but there is actually some degree of physiological response specificity, allowing particular response patterns to be associated with discrete emotional states (Hodges, 2016; Kreibig, 2010). Further research using 
a wider range of physiological responses could help identify which emotions are most closely related to MECs.

\subsubsection{Neural correlates}

In Section 3.5, we found that MECs involve the recruitment of brain structures associated with emotion, reward, pleasure, reinforcement, motivation, arousal, and motor processes (Blood \& Zatorre, 2001; Brattico et al., 2009; Chanda \& Levitin, 2013; Vuust \& Kringelbach, 2010), and display activation patterns consistent with the reward experienced in response to food, sex, and drugs, notably through the involvement of dopaminergic and opioid systems (Blood \& Zatorre, 2001; Chanda \& Levitin, 2013; Mallik et al., 2017; Zatorre, 2003). Additionally, evidence suggests that individual differences in the experience of MECs might be due, in part, to differences in white matter connectivity between auditory and reward systems (Brattico, 2019; Hernández et al., 2019; Loui et al., 2017; Sachs et al., 2016).

Limitations of this body of work include poor generalisability due to small sample sizes and participants sometimes being selected for their ability to reliably experience MECs (e.g., Blood \& Zatorre, 2001; Salimpoor et al., 2011), the poor time resolution of positron emission tomography, used in the study by Salimpoor et al. (2011), resulting in uncertainty about the precise timing of dopamine release (Habibi \& Damasio, 2014; Vuust \& Kringelbach, 2010), and finally, reliance on drawing reverse inferences about psychological mechanisms from observations of activation in brain areas subserving a broad range of psychological functions (Konečni, 2005; Logothetis, 2008; Poldrack, 2011). Overall, however, the consistency of the findings across a broad range of methods (neuroimaging, neurochemical, and lesion studies) provides strong support for the involvement of limbic and reward-related brain regions during MECs. A challenge for future research will be to understand if there are any patterns of neural activation which distinguish MECs from other instances of reward and pleasure.

\subsubsection{Elicitors}

Some authors have reported a lack of clear stimulus-response pattern with the experience of MECs (Bannister, 2020a; Grewe et al., 2007; Nagel et al., 2008), and while it is certainly true that a specific musical passage does not reliably cause MECs for all people (see Subsection 3.3.3), the evidence reviewed in Section 3.6 strongly points towards a set of acoustic, musical, and emotional elicitors being involved in the experience of MECs, including dynamic changes, increased roughness, crescendi, unexpected structural changes, textural changes, and perceived emotionality. Through underlying mechanisms, such as brain stem reflex and expectation, and associated factors, such as attention and familiarity, it is likely that, as is the case with aesthetic and emotional responses to music (Gabrielsson, 2011; Hargreaves, 2012; Juslin, 2013; Juslin \& Västfjäll, 2008; Scherer et al., 2001), MECs rely on an interaction between listener (see Section 3.7), context (about which there is currently relatively little research, although 
see Subsection 3.6.5), and music (see Section 3.6). Importantly, most of the research discussed in Section 3.6 relies on correlational evidence, which weakens its strength. However, efforts have been made in recent research to use systematic manipulations in order to establish causality (see Subsection 3.3.3), confirming loudness and textural changes as elicitors of chills, for instance, and therefore resulting in a more robust understanding of the causes of MECs.

\subsubsection{Individual differences}

In Section 3.7, we found that in general, evidence for the influence of individual differences on the experience of MECs is mixed. This might be a consequence of most of these individual differences being studied in the context of exploratory research with little theoretical basis, with the exception of some of the Big Five personality traits (including openness to experience), as well as reward sensitivity, stylistic preference, and trait empathy. Regardless, from the totality of the evidence reviewed, it is now well established that openness to experience plays a role, and in more general terms, that personality differences affect who experiences MECs, and how often they are experienced. This should be taken into consideration when researching MECs, because individuals might react differently to various experimental situations, based on their personality characteristics.

\subsubsection{Theoretical perspectives on function}

At present, the theoretical accounts for MECs reviewed in Section 3.8 lag behind the empirical evidence in terms of their breadth, depth, degree of empirical corroboration, and ability to make clear and distinctive empirical predictions. Considering the diversity of empirical findings about MECs, it seems increasingly unlikely that a single functional mechanism could provide an adequate explanation for why they occur. There is currently little empirical evidence that specifically supports the separation call and knowledge instinct theories. Taken together, however, contrastive valence, peak arousal and pleasure, and the emotional state of being moved could account for much of the empirical evidence. It therefore seems plausible that competing theoretical perspectives based on evolutionary expectation and social processes might together explain the diversity in elicitors and personality characteristics involved in the experience of MECs (see Bannister, 2019).

It is worth emphasising again that all the theoretical perspectives on the function of MECs reviewed here are speculative, and would greatly benefit from the use of cross-cultural (see Beier et al., 2020), and developmental research, both of which (and ideally in combination) would provide evidence regarding the role of culturally-embedded learning in determining the elicitors and experience of MECs, as well as any potential evolutionary basis for their existence. In addition, hypothesis-based experiments testing the concrete predictions of the most promising theories are needed for further corroboration. In particular, the individual theories make different predictions about the psychological circum- 
stances in which MECs would be experienced - during an experience of being moved (due to social closeness and empathy), during an experience of contrastive valence or auditory looming, or during an experience of high levels of emotional arousal or pleasure. Empirical experiments that test these predictions against one another are necessary to provide further clarity on the theoretical basis of MECs. Again, we would emphasise that it seems very possible that more than one psychological mechanism will be required to account for different kinds of chills.

\subsection{Integration of findings}

In this section, we integrate and expand upon the main findings from the reviewed literature in order to address the important questions raised in the introduction.

First, MECs seem to be relatively universal, as they are experienced by up to $90 \%$ of the surveyed population. However, while they are experienced with some degree of regularity, they remain a rare occurrence, with gaps between MECs sometimes reaching weeks or months for some people. This has no bearing on whether or not these experiences are meaningful to those who experience them, but it raises questions about their suitability for empirical research on emotional and aesthetic responses to music. Indeed, even though MECs are pleasurable, if they are rarely experienced, they are unlikely to provide a full picture of the aesthetic experience of music. Moreover, the fact that MECs are experienced by a smaller proportion of the population in experimental settings suggests that such settings may be inappropriate for the study of the entire range of aesthetic responses to music. However, the fact remains that MECs are pleasurable (see Subsection 3.2.2), and that despite their relatively sparse occurrence, they do reliably occur in experimental settings and are arguably the most convenient, objectively observable empirical measure of pleasure experienced in response to music listening (see Subsection 4.1.2). As long as care is taken not to place undue focus on MECs being representative of all aesthetic responses to music, we believe that they are worthy of scientific inquiry and have the potential to reveal much about how music is processed and about music appreciation.

Second, we argued that while MECs exhibit some characteristics consistent with emotional responses, the lack of clear motor expression and action tendency suggests that they should not be considered as an emotional state per se. This argument could reasonably be debated. Brain structures associated with motor processes are recruited during MECs (see Subsection 3.2.1), possibly suggesting preparedness for singing and dancing (Brattico \& Pearce, 2013), and to our knowledge, there has been no investigation of facial muscle activation in MECs. Moreover, a possible action tendency exhibited by MECs could consist of a focus of attention towards aesthetic stimuli (see Subsection 3.2.3). It could therefore be argued that MECs are indeed an emotional reaction, or at least, the manifestation of an extreme emotional reaction. While we are inclined to consider MECs as a psychophysiological response which can form part of a range of emotional states, further research is needed to establish the precise relationship between MECs and emotions. Regarding the relationship between MECs and 
aesthetic responses, the evidence strongly suggests that MECs are perceived as pleasurable (see Subsection 3.2.2). While there are reports of displeasurable chills, they tend to occur in reaction to non-musical stimuli, and we therefore surmise that most, if not all, MECs are pleasurable, possibly because music listening itself is generally a pleasurable activity. However, MECs are often used as an empirical indicator of peak pleasure, despite there being relatively little evidence in support of this claim. In our opinion, conflating MECs and peak pleasure misrepresents the relevance of MECs to research on music emotion and aesthetics. We believe that research on MECs contributes usefully to the literature on emotional and aesthetic responses to music, as long as MECs are not considered as fully fledged emotional and aesthetic responses, but rather as non-obligatory but enhancing components of these responses.

Third, we reviewed two articles which suggest that chills represent a collection of phenomenologically and psychologically distinct experiences (see Subsection 3.1.4). These are, to our knowledge, the only contributions studying this question from an empirical point of view. However, it is worth emphasising that in both cases, several stimulus modalities were investigated, as opposed to music only, and it is not yet known whether or not MECs specifically are a multi-faceted phenomenon as well. We believe it is likely that MECs can arise from different combinations of elicitors and associated underlying mechanisms, which could be explained by different theoretical perspectives on the function of MECs, but it remains to be determined whether these would lead to different types of MECs, or to the same psychophysiological response in all cases. The implications for past and future research on MECs are considerable, because failing to distinguish between different types of MECs could lead to null, conflicting, or misleading empirical findings. We therefore believe that investigating this question should be a priority for research on MECs.

Fourth, the evidence suggests that there are great similarities between the physiological and neural correlates of MECs and pleasurable responses to music in the absence of MECs (see Archie et al., 2013; Koelsch, 2010, 2014; Salimpoor et al., 2011), and that so far, there does not seem to be any physiological or neural signature setting these two responses apart. This is due to the fact that, as discussed above, MECs and pleasure are tightly coupled. There have been no studies investigating this specific issue, so for the moment being, the only available evidence relies on drawing inferences from tangential findings. In a lesion study (Grunkina et al., 2017) and in a study about anhedonia (Mas-Herrero et al., 2014), there have been reports of participants experiencing MECs with an impaired ability to experience pleasure, which would suggest that these two responses are not always associated. However, in both cases, it is not possible to establish if these participants had the ability to experience some residual degree of pleasure. It is therefore not currently possible to establish whether MECs invoke general-purpose mechanisms involved in emotional processing and reward, or dedicated neural and physiological machinery instead. We suspect that there are specific neural and physiological signatures for MECs, but that they will only be uncovered in a systematic empirical comparison between MECs and other highly pleasurable experiences of music. 
Finally, while we have already discussed causes of MECs in this review, it is worth integrating the evidence on their elicitors, individual differences, and origins. The evidence suggests that while MECs are idiosyncratic to some extent, stimulus-driven characteristics, such as changes in loudness, crescendi, or emotionality, strongly drive their occurrence (see Section 3.6). In terms of individual differences, there was no clear effect of age, gender, or musical training, but we believe individual differences should not be dismissed just yet. If expectation is involved in MECs, there could be an effect of musical training, since musicians tend to develop more precise expectations (Hansen \& Pearce, 2014; Hansen et al., 2016; Quiroga-Martinez et al., 2019), or an effect of individual differences in music perception abilities. Openness to experience was identified as strongly associated with MECs. This personality trait is associated with preference for sophisticated, intense, and mellow music (Schäfer \& Mehlhorn, 2017), which could imply that individuals with high scores on openness to experience seek out music which features violations of expectation or high emotionality. In terms of theoretical accounts of the function of MECs, the approaches most consistent with the available evidence are that MECs occur because of the emotional state of being moved, peak arousal, or contrastive valence. Further research is needed to test these theories against one another. However, it is also possible that all these theories account for different aspects of MECs. As discussed above, we speculate that, regardless of whether there exists different types of MECs or not, it is possible that there are different causes of MECs. For instance, acoustic elicitors could engage the mechanism of brain stem reflex, causing MECs through peak arousal, the function of which is perhaps associated to a need to maintain homeostatic balance. Musical elicitors could engage musical expectation, causing MECs through the evolutionary fear-based process of contrastive valence. And finally, emotional elicitors could engage the mechanism of emotional contagion, causing MECs through the evolutionary social process of being moved. This would signify that MECs rely on an interaction between listener, context, and music, which is itself driven by psychological mechanisms of emotional responses to music and evolutionary reasons for the function of MECs.

\subsection{Framework for future research}

We conclude this review by providing a tentative, preliminary framework for future research on MECs. We begin with a set of minimum criteria for a response to music to be considered as MECs. We then provide a model of MECs based on the reviewed literature and a dataset of pieces of music known to cause MECs, before delineating open issues, hypotheses, and recommended approaches.

\subsubsection{Criteria for music-evoked chills}

We provide here a preliminary set of minimum criteria for MECs. These criteria rely, in part, on our current, subjective interpretation of the strength of the available evidence, and will certainly be subject to change as research on MECs 
progresses. They are also conservative, only including criteria which the evidence suggests are almost certainly associated with MECs, but not criteria based on other findings which have yet to produce consensus.

We argue that, for a typical individual's response to music to be categorised as MECs, this response should be a sudden, fleeting, and pleasurable physical reaction to music-driven properties (whether they are acoustic, musical, or emotional), most commonly originating from the head, neck, back, or arms. Its occurrence should be possible in a large proportion of the population, and particularly by individuals with high openness to experience. It should involve increases in subjective arousal, skin conductance response, and heart rate, as well as limbic and reward-related neural activity. This response might but does not necessarily involve piloerection, and forms part of an emotional or aesthetic experience of music, though emotional or aesthetic experiences of music need not necessarily involve this response.

\subsubsection{Model of music-evoked chills}

The criteria presented above are integrated with the rest of the literature in a preliminary model for the experience of MECs, in order to provide a framework which will allow the formulation of hypotheses for future research on MECs. This model is not exhaustive, but it includes a range of parameters, mechanisms, and response attributes we believe to be the most relevant to future investigation of MECs.

The model is presented in Figure 2. Parameters represent the interaction between listener, music, and context that is most likely involved in MECs. This aggregation of parameters gives rise to the response of MECs, through the combination of the psychological and evolutionary mechanisms we identified as the most likely to underlie MECs. We included elements which lack full empirical verification, but which, in our view, represent important open issues in research on MECs, such as the effect of attention, the exact nature of the psychological mechanisms which lead to MECs, or the extent of the relationship between aesthetic and emotional responses and MECs. A distinguishing feature of this model is that it also groups phenomena which we believe could be related across categories, and could provide different pathways for the experience of MECs, if not different types of MECs. For instance, it could be that individuals with high trait empathy, perceiving emotional elicitors when listening to music, mimic the perceived emotion through emotional contagion, leading to MECs (or even to a distinct type of emotion-induced MECs) through the process of being moved. While such predictions are preliminary, they integrate existing findings, highlight important open issues, and allow the formulation of new hypotheses, providing a path towards a better understanding of MECs.

\subsubsection{Dataset of music-evoked chills}

Empirical studies of music-evoked emotions most often feature stimuli pertaining to MECs (Warrenburg, 2020), such that a large quantity of music which can 


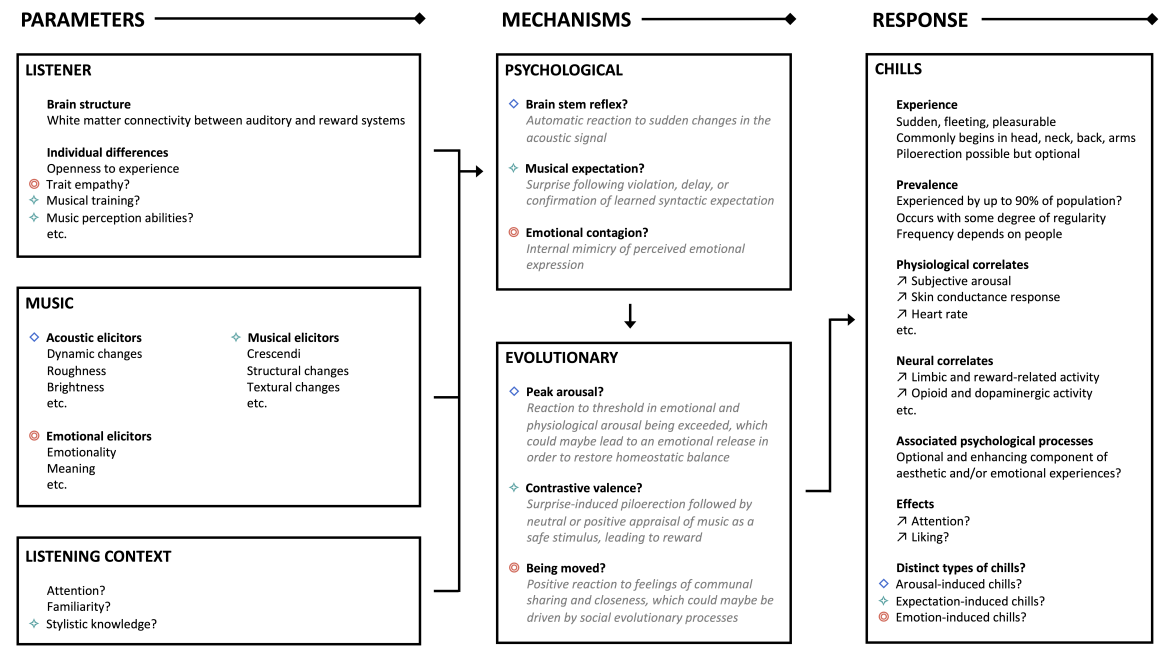

Figure 2: Preliminary model of music-evoked chills. Parameters on the left represent factors which influence the response of music-evoked chills on the right, via psychological and evolutionary mechanisms in the middle. Diagonal arrows represent increases in the associated response. Sentences in italics represent definitions for the listed mechanisms. Question marks represent open questions which lack empirical corroboration. The term "etc." indicates categories for which future evidence or replication of current evidence may warrant the addition of further entries. Symbols link together phenomena which could be related, and could contribute to distinct experiences of music-evoked chills.

cause MECs has been documented in the academic literature on MECs. With the aim of facilitating more integrated research on MECs, we have compiled Chills in Music (ChiM), a dataset which contains, to our knowledge, all pieces of music which have been reported to elicit MECs in the literature reviewed in this article $^{2}$. It should be noted that the dataset contains little information about the timing of MECs in most pieces of music, due to limited information in the reviewed literature. Efforts should be expanded to augment ChiM with precise timing information, in order to support future computational research on MECs.

\subsubsection{Open issues and recommendations}

In this section, we highlight open issues in the literature on MECs, based on the reviewed literature and on the preliminary model presented above. In our view, investigating these issues has the most potential to advance research on MECs. Throughout this systematic review, we also identified significant methodological shortcomings regarding research design, adequacy of experimental variables,

${ }^{2} \mathrm{ChiM}$ is available at https://doi.org/10.17605/osf.io/uyg7m. 


\begin{tabular}{|c|c|c|}
\hline Open issue & Hypothesis & Suggested approach \\
\hline $\begin{array}{l}\text { Universality of } \\
\text { chills }\end{array}$ & $\begin{array}{l}\text { MECs are experienced by the same } \\
\text { proportion of the population, regardless of } \\
\text { culture, but are dependent on } \\
\text { enculturation. }\end{array}$ & $\begin{array}{l}\text { Conduct a large-scale, cross-cultural survey of MECs, recording information } \\
\text { about exposure to various musical cultures and genres. }\end{array}$ \\
\hline $\begin{array}{l}\text { Occurrence of } \\
\text { piloerection }\end{array}$ & $\begin{array}{l}\text { Piloerection occurs once MECs exceed an } \\
\text { intensity threshold. }\end{array}$ & $\begin{array}{l}\text { Record self-reported intensity of MECs and compare to measured piloerection. } \\
\text { This might require further validation or development of piloerection sensors. }\end{array}$ \\
\hline $\begin{array}{l}\text { Specificity of } \\
\text { MECs }\end{array}$ & $\begin{array}{l}\text { MECs exhibit different physiological and } \\
\text { neural signatures than those of emotion or } \\
\text { pleasure. }\end{array}$ & $\begin{array}{l}\text { Compare responses with self-selected music that can elicit distinct experiences of } \\
\text { MECs, emotion, and pleasure. If there is specificity, a classifier could be trained } \\
\text { to distinguish unlabelled instances of MECs from emotional and pleasurable } \\
\text { episodes without MECs. }\end{array}$ \\
\hline $\begin{array}{l}\text { Acoustic and } \\
\text { musical } \\
\text { elicitors }\end{array}$ & $\begin{array}{l}\text { The effect of acoustic elicitors on MECs is } \\
\text { partially mediated by musical elicitors, } \\
\text { and vice versa. }\end{array}$ & $\begin{array}{l}\text { Compare extracted acoustic and musical features (using music information } \\
\text { retrieval and/or manual annotation) around the onset of MECs (using a dataset } \\
\text { such as the one provided in this review). Alternatively, systematically } \\
\text { manipulate stimuli to independently vary the two types of elicitors and compare } \\
\text { occurrences of MECs. }\end{array}$ \\
\hline Familiarity & $\begin{array}{l}\text { MECs are experienced more frequently as } \\
\text { familiarity increases. }\end{array}$ & $\begin{array}{l}\text { Use a longitudinal design to study the progress of the frequency of MECs when } \\
\text { repeatedly exposed to previously unfamiliar and familiar music with the } \\
\text { potential to elicit MECs. }\end{array}$ \\
\hline $\begin{array}{l}\text { MECs and } \\
\text { attention }\end{array}$ & $\begin{array}{l}\text { Attending to music increases the } \\
\text { likelihood of MECs occurring, and MECs } \\
\text { focus attention towards the eliciting } \\
\text { music. }\end{array}$ & $\begin{array}{l}\text { Assess the occurrence of MECs at rest and during a non-musical distractor task } \\
\text { while listening to music. Fewer MECs should occur while distracted, and if they } \\
\text { occur, they should impair performance on the task. }\end{array}$ \\
\hline $\begin{array}{l}\text { Psychological } \\
\text { mechanisms }\end{array}$ & $\begin{array}{l}\text { Exploratory animal and developmental } \\
\text { research can help pinpoint the } \\
\text { psychological and neural mechanisms } \\
\text { underlying MECs. }\end{array}$ & $\begin{array}{l}\text { Since brain stem reflex, musical expectation, and emotional contagion rely on } \\
\text { different psychological and neural mechanisms, which might be more or less well } \\
\text { developed in different species and at different developmental stages, exploring } \\
\text { the prevalence of MECs in animals and individuals varying in developmental age } \\
\text { could shed light on the mechanisms underlying MECs, and identify } \\
\text { developmental trajectories. }\end{array}$ \\
\hline Peak arousal & $\begin{array}{l}\text { MECs can occur in response to peaks in } \\
\text { arousal or pleasure, but might not always } \\
\text { since several mechanisms drive the } \\
\text { occurrence of MECs. }\end{array}$ & $\begin{array}{l}\text { Record measures of physiological arousal for a large number of MECs to identify } \\
\text { a threshold for peak arousal or subjective pleasure. MECs should happen every } \\
\text { time this threshold is exceeded, but could also happen below this threshold if } \\
\text { elicited by a different mechanism. }\end{array}$ \\
\hline $\begin{array}{l}\text { Musical } \\
\text { expectation }\end{array}$ & $\begin{array}{l}\text { MECs can occur in response to violations } \\
\text { of expectation, but might not always since } \\
\text { several mechanisms drive the occurrence } \\
\text { of MECs. }\end{array}$ & $\begin{array}{l}\text { Collect precise timing information for when MECs occur (or use the dataset } \\
\text { provided in this review), and compare them to the output from a computational } \\
\text { model of expectation. MECs should always occur for sufficiently strong } \\
\text { violations of expectation but might occur elsewhere if elicited by a different } \\
\text { mechanism. }\end{array}$ \\
\hline $\begin{array}{l}\text { Evolutionary } \\
\text { mechanisms* }\end{array}$ & $\begin{array}{l}\text { MECs can occur via either peak arousal, } \\
\text { contrastive valence, or the process of } \\
\text { being moved. }\end{array}$ & $\begin{array}{l}\text { Carefully prepare stimuli with the potential to elicit MECs via these three } \\
\text { mechanisms, controlling for the others, and collect continuous measures (for } \\
\text { instance, the two measures detailed above for peak arousal and expectation, and } \\
\text { self-reports for being moved). Peaks for each measure should correspond to the } \\
\text { onset of MECs for each targeted mechanism. }\end{array}$ \\
\hline $\begin{array}{l}\text { Listener and } \\
\text { context* }\end{array}$ & $\begin{array}{l}\text { Susceptibility to MECs caused via } \\
\text { different mechanisms is partly governed } \\
\text { by individual differences, familiarity, and } \\
\text { stylistic knowledge. }\end{array}$ & $\begin{array}{l}\text { Using the approach detailed above, compare individual differences and } \\
\text { personality correlates across participants who reported the most MECs for each } \\
\text { mechanism. Include familiarity and stylistic knowledge for each piece of music as } \\
\text { a random effect in a mixed effect model. }\end{array}$ \\
\hline $\begin{array}{l}\text { Distinct types } \\
\text { of MECs* }\end{array}$ & $\begin{array}{l}\text { Different parameters and mechanisms } \\
\text { cause different types of MECs, with } \\
\text { distinct physiological and neural } \\
\text { signatures. }\end{array}$ & $\begin{array}{l}\text { Similarly, using the approach detailed above, compare physiological and neural } \\
\text { correlates for MECs elicited via each mechanism. Alternatively, collect these } \\
\text { measures along with qualitative descriptions of MECs to identify differences } \\
\text { between different categories of MECs. }\end{array}$ \\
\hline
\end{tabular}

Table 7: Open issues, hypotheses, and suggested approaches for future research on music-evoked chills

measures of MECs, and terminology. We provide suggestions for addressing these shortcomings below.

Table 7 lists what we consider to be the most important open issues in the available evidence on MECs, along with hypotheses and recommended experimental approaches. While all these issues are derived from the model of MECs we provided, we make a distinction between issues arising from the reviewed literature, and specific predictions arising from the proposed model. 
Throughout this review, we have provided methodological recommendations to address shortcomings in the research on MECs. Notably, we recommended that piloerection should not be used as the sole indicator of MECs (Subsection 3.1.2), that MECs should not be used as the sole indicator of emotional and aesthetic responses (Subsection 4.1.2), and that individual differences should be taken into account (Subsection 4.1.7), particularly because chills could be a multi-faceted phenomenon, which could lead to null, conflicting, or misleading results if this is not taken into consideration (Subsection 3.1.4). We argued that a combination of self-reports and objective measures are best suited for the study of MECs (Subsection 4.1.3), and that care should be taken when validating self-reports of MECs with skin conductance response (Subsection 3.3.1). Finally, we recommended the use of the terms chills and piloerection (Subsection 3.1.1), and suggest a definition for participants in research on MECs, characterising MECs as a fleeting, pleasurable bodily sensation, sometimes accompanied by goosebumps, experienced when listening to specific musical passages.

\subsection{Conclusion}

We conducted a systematic review of the literature on MECs. Theoretical and empirical findings were integrated, leading to the conclusion that MECs are a prevalent psychophysiological response which can include piloerection, and a pleasurable, though not essential, component of emotional and aesthetic experiences. They have been studied using both subjective and objective measures, with a recent focus on causal approaches - a necessary endeavour due to most of the evidence being correlational in nature, and therefore often difficult to interpret. In terms of biological basis, MECs are associated with physiological changes and increased arousal, and recruit brain structures and systems relevant to emotion, reward, and motivation. We reviewed many possible causes of MECs in this article. In light of the quality and quantity of the evidence, we believe certain factors to be of particular importance. Notably, MECs can be elicited by acoustic, musical, and emotional stimulus-driven properties which, taken together, suggest a prominent role of sudden changes in acoustic properties, of high-level structural prediction, and of emotionality. They are influenced by personality differences, and especially openness to experience, which is a strong predictor of the ability to experience MECs. Finally, the more convincing theoretical accounts of the function of MECs suggest an involvement of mechanisms based on expectation, peak emotion, and being moved.

We concluded this review by establishing a preliminary framework for future research on MECs, providing a set of minimum criteria for a response to music to be considered as an instance of MECs, a model of MECs that explicitly allows for different psychological pathways for the experience of MECs and different types of MECs, a dataset of pieces of music known to cause MECs, and a list of open issues, hypotheses, and potential experiment approaches. 


\section{Acknowledgements}

We thank Emmanouil Benetos, Ana Clemente, and the reviewers for their valuable feedback on previous versions of this article.

\section{Funding source}

This work was supported by the EPSRC and AHRC Centre for Doctoral Training in Media and Arts Technology [EP/L01632X/1].

\section{Declaration of interest}

None.

\section{References}

Altenmüller, E., Kopiez, R., \& Grewe, O. (2013). A contribution to the evolutionary basis of music: Lessons from the chill response. In E. Altenmüller, S. Schmidt, \& E. Zimmermann (Eds.), Evolution of emotional communication: From sounds in nonhuman mammals to speech and music in man (pp. 313-335). Oxford University Press. https://doi.org/10.1093/acprof: oso/9780199583560.003.0019

Archie, P., Bruera, E., \& Cohen, L. (2013). Music-based interventions in palliative cancer care: A review of quantitative studies and neurobiological literature. Support. Care Cancer, 21, 2609-2624. https://doi.org/10. 1007/s00520-013-1841-4

Auricchio, N. (2017). Natural highs: Timbre and chills in electronic dance music. In J. Merrill (Ed.), Popular music studies today: Proceedings of the International Association for the Study of Popular Music 2017 (pp. 1123). Springer. https://doi.org/10.1007/978-3-658-17740-9_1

Balteș, R. F., Avram, J., Miclea, M., \& Miu, A. C. (2011). Emotions induced by operatic music: Psychophysiological effects of music, plot, and acting: A scientist's tribute to Maria Callas. Brain Cogn., 76 (1), 146-157. https: //doi.org/10.1016/j.bandc.2011.01.012

Balteș, R. F., \& Miu, A. C. (2014). Emotions during live music performance: Links with individual differences in empathy, visual imagery, and mood. Psychomusicology Music Mind Brain, 24(1), 58-65. https://doi.org/10. 1037/pmu0000030

Bannister, S. (2019). Distinct varieties of aesthetic chills in response to multimedia. PLOS ONE, 14(11), e0224974. https://doi.org/10.1371/journal. pone.0224974

Bannister, S. (2020a). A survey into the experience of musically induced chills: Emotions, situations and music. Psychol. Music, 48(2), 297-314. https: //doi.org/10.1177/0305735618798024 
Bannister, S. (2020b). A vigilance explanation of musical chills? Effects of loudness and brightness manipulations. Music Sci., 3, 1-17. https://doi. org $/ 10.1177 / 2059204320915654$

Bannister, S., \& Eerola, T. (2018). Suppressing the chills: Effects of musical manipulation on the chills response. Front. Psychol., 9, 2046. https: //doi.org/10.3389/fpsyg.2018.02046

Beier, E. J., Janata, P., Hulbert, J. C., \& Ferreira, F. (2020). Do you chill when I chill? A cross-cultural study of strong emotional responses to music. Psychol. Aesthet. Creat. Arts, Advance online publication. https: //doi.org/10.1037/aca0000310

Benedek, M., \& Kaernbach, C. (2011). Physiological correlates and emotional specificity of human piloerection. Biol. Psychol., 86 (3), 320-329. https: //doi.org/10.1016/j.biopsycho.2010.12.012

Benedek, M., Wilfling, B., Lukas-Wolfbauer, R., Katzur, B. H., \& Kaernbach, C. (2010). Objective and continuous measurement of piloerection. Psychophysiology, 47(5), 989-993. https:// doi.org/10.1111/j.14698986.2010.01003.x

Bériachvili, G. (2016). Frisson esthétique: À la recherche d'une explication théorique. Int. Rev. Aesthet. Sociol. Music, 47(1), 63-85.

Bharucha, J. J. (1994). Tonality and expectation. In R. Aiello \& J. A. Sloboda (Eds.), Musical perceptions (pp. 213-239). Oxford University Press.

Bicknell, J. (2007). Explaining strong emotional responses to music: Sociality and intimacy. J. Conscious. Stud., 14 (12), 5-23.

Blood, A. J., \& Zatorre, R. J. (2001). Intensely pleasurable responses to music correlate with activity in brain regions implicated in reward and emotion. Proc. Natl. Acad. Sci. U.S.A., 98(20), 11818-11823. https://doi.org/10. 1073/pnas.191355898

Branković, S. (2013). Neuroaesthetics and growing interest in "positive affect" in psychiatry: New evidence and prospects for the theory of informational needs. Psychiatr. Danub., 25(2), 97-107.

Brattico, E. (2019). The neuroaesthetics of music: A research agenda coming of age. In M. H. Thaut \& D. A. Hodges (Eds.), The Oxford handbook of music and the brain (pp. 364-390). Oxford University Press. https: //doi.org/10.1093/oxfordhb/9780198804123.013.15

Brattico, E., Bogert, B., \& Jacobsen, T. (2013). Toward a neural chronometry for the aesthetic experience of music. Front. Psychol., 4, 206. https: //doi.org/10.3389/fpsyg.2013.00206

Brattico, E., Brattico, P., \& Jacobsen, T. (2009). The origins of the aesthetic enjoyment of music - A review of the literature. Music. Sci., 13 (Suppl. 2), 15-39. https://doi.org/10.1177/1029864909013002031

Brattico, E., \& Pearce, M. T. (2013). The neuroaesthetics of music. Psychol. Aesthet. Creat. Arts, 7(1), 48-61. https://doi.org/10.1037/a0031624

Brattico, E., \& Varankaite, U. (2019). Aesthetic empowerment through music. Music. Sci., 23(3), 285-303. https://doi.org/10.1177/1029864919850606 
Cantor, R. M. (2019). On the embodied meaning of emotional responses to music: A semiotic perspective. Semiotica, 231, 225-244. https://doi.org/10. 1515/sem-2018-0039

Carr, S. M., \& Rickard, N. S. (2016). The use of emotionally arousing music to enhance memory for subsequently presented images. Psychol. Music, 44(5), 1145-1157. https://doi.org/10.1177/0305735615613846

Chabin, T., Tio, G., Comte, A., Joucla, C., Gabriel, D., \& Pazart, L. (2020). The relevance of a conductor competition for the study of emotional synchronization within and between groups in a natural music setting. Front. Psychol., 10, 2954. https://doi.org/10.3389/fpsyg.2019.02954

Chanda, M. L., \& Levitin, D. J. (2013). The neurochemistry of music. Trends Cogn. Sci., 17(4), 179-193. https://doi.org/10.1016/j.tics.2013.02.007

Cheung, V. K. M., Harrison, P. M. C., Meyer, L., Pearce, M. T., Haynes, J.-D., \& Koelsch, S. (2019). Uncertainty and surprise jointly predict musical pleasure and amygdala, hippocampus, and auditory cortex activity. Curr. Biol., 29(23), 4084-4092. https://doi.org/10.1016/j.cub.2019.09.067

Colver, M. C., \& El-Alayli, A. (2016). Getting aesthetic chills from music: The connection between openness to experience and frisson. Psychol. Music, 44 (3), 413-427. https://doi.org/10.1177/0305735615572358

Corrigall, K. A., \& Schellenberg, E. G. (2013). Music: The language of emotion. In C. Mohiyeddini, M. Eysenck, \& S. Bauer (Eds.), Handbook of psychology of emotions: Recent theoretical perspectives and novel empirical findings (pp. 299-326). Nova Science Publishers.

Corrigall, K. A., \& Schellenberg, E. G. (2015). Liking music: Genres, contextual factors, and individual differences. In J. P. Huston, M. Nadal, F. Mora, L. F. Agnati, \& C. J. C. Conde (Eds.), Art, aesthetics, and the brain (pp. 263-284). Oxford University Press. https://doi.org/10.1093/acprof: oso $/ 9780199670000.003 .0013$

Costa, P. T., \& McCrae, R. R. (1992). Revised NEO Personality Inventory (NEO-PI-R) and NEO Five-Factor Inventory (NEO-FFI) professional manual. Psychological Assessment Resources.

Cotter, K. N., Prince, A. N., Christensen, A. P., \& Silvia, P. J. (2019). Feeling like crying when listening to music: Exploring musical and contextual features. Empir. Stud. Arts, 37(2), 119-137. https://doi.org/10.1177/ 0276237418805692

Cotter, K. N., Silvia, P. J., \& Fayn, K. (2018). What does feeling like crying when listening to music feel like? Psychol. Aesthet. Creat. Arts, 12(2), 216-227. https://doi.org/10.1037/aca0000108

Craig, D. G. (2005). An exploratory study of physiological changes during "chills" induced by music. Music. Sci., 9(2), 273-287. https://doi.org/10.1177/ 102986490500900207

Craig, D. G. (2009). Exploring music preference: Meaningfulness of music as a function of emotional reactions. Nord. J. Music Ther., 18(1), 57-69. https://doi.org/10.1080/08098130802697137

del Campo, M. A., \& Kehle, T. J. (2016). Autonomous sensory meridian response (asmr) and frisson: Mindfully induced sensory phenomena that promote 
happiness. Int. J. School Educ. Psychol., 4(2), 99-105. https://doi.org/ 10.1080/21683603.2016.1130582

Dowd, E. C., \& Barch, D. M. (2012). Pavlovian reward prediction and receipt in schizophrenia: Relationship to anhedonia. PLOS ONE, 7(5), e35622. https://doi.org/10.1371/journal.pone.0035622

Dubé, L., \& Le Bel, J. (2003). The content and structure of laypeople's concept of pleasure. Cogn. Emot., 17(2), 263-295. https://doi.org/10.1080/ 02699930302295

Eerola, T. (2018). Music and emotions. In R. Bader (Ed.), Springer handbook of systematic musicology (pp. 539-554). Springer. https://doi.org/10.1007/ 978-3-662-55004-5_29

Eerola, T., Vuoskoski, J. K., \& Kautiainen, H. (2016). Being moved by unfamiliar sad music is associated with high empathy. Front. Psychol., 7, 1176. https://doi.org/10.3389/fpsyg.2016.01176

Egermann, H., Sutherland, M. E., Grewe, O., Nagel, F., Kopiez, R., \& Altenmüller, E. (2011). Does music listening in a social context alter experience? A physiological and psychological perspective on emotion. Music. Sci., 15(3), 307-323. https://doi.org/10.1177/1029864911399497

Essen, D. C. V., Smith, S. M., Barch, D. M., Behrens, T. E. J., Yacoub, E., \& Ugurbil, K. (2013). The WU-Minn Human Connectome Project: An overview. NeuroImage, 80, 62-79. https://doi.org/10.1016/j.neuroimage. 2013.05.041

Ferreri, L., Mas-Herrero, E., Zatorre, R. J., Ripollés, P., Gomez-Andres, A., Alicart, H., Olivé, G., Marco-Pallarés, J., Antonijoan, R. M., Valle, M., Riba, J., \& Rodriguez-Fornells, A. (2019). Dopamine modulates the reward experiences elicited by music. Proc. Natl. Acad. Sci. U.S.A., 116 (9), 3793-3798. https://doi.org/10.1073/pnas.1811878116

Fiske, A. P., Seibt, B., \& Schubert, T. W. (2019). The sudden devotion emotion: Kama muta and the cultural practices whose function is to evoke it. Emot. Rev., 11(1), 74-86. https://doi.org/10.1177/1754073917723167

Fukui, H., \& Toyoshima, K. (2013). Influence of music on steroid hormones and the relationship between receptor polymorphisms and musical ability: A pilot study. Front. Psychol., 4, 910. https://doi.org/10.3389/fpsyg.2013. 00910

Fukui, H., \& Toyoshima, K. (2014). Chill-inducing music enhances altruism in humans. Front. Psychol., 5, 1215. https://doi.org/10.3389/fpsyg.2014. 01215

Fukushima, S., \& Kajimoto, H. (2012). Facilitating a surprised feeling by artificial control of piloerection on the forearm. In J.-M. Seigneur (Ed.), Proceedings of the 3rd Augmented Human International Conference, AH '12 (pp. 1-4). Association for Computing Machinery. https://doi.org/10. $1145 / 2160125.2160133$

Gabrielsson, A. (2001). Emotions in strong experiences with music. In P. N. Juslin \& J. A. Sloboda (Eds.), Music and emotion: Theory and research (pp. 431-449). Oxford University Press. 
Gabrielsson, A. (2011). Strong experiences with music: Music is much more than just music. Oxford University Press. https://doi.org/10.1093/acprof: oso/9780199695225.001.0001

Gabrielsson, A., Whaley, J., \& Sloboda, J. (2016). Peak experiences in music. In S. Hallam, I. Cross, \& M. Thaut (Eds.), The Oxford handbook of music psychology (2nd, pp. 745-758). Oxford University Press. https: //doi.org/10.1093/oxfordhb/9780198722946.013.44

Gabrielsson, A., \& Wik, S. L. (2003). Strong experiences related to music: A descriptive system. Music. Sci., 7(2), 157-217. https://doi.org/10.1177/ 102986490300700201

Gold, B. P., Pearce, M. T., Mas-Herrero, E., Dagher, A., \& Zatorre, R. J. (2019). Predictability and uncertainty in the pleasure of music: A reward for learning? J. Neurosci., 39(47), 9397-9409. https://doi.org/10.1523/ jneurosci.0428-19.2019

Goldstein, A. (1980). Thrills in response to music and other stimuli. Physiol. Psychol., 8(1), 126-129. https://doi.org/10.3758/bf03326460

Goodchild, M., Wild, J., \& McAdams, S. (2019). Exploring emotional responses to orchestral gestures. Music. Sci., 23(1), 25-49. https://doi.org/10. $1177 / 1029864917704033$

Grahn, J. A., \& Brett, M. (2007). Rhythm and beat perception in motor areas of the brain. J. Cogn. Neurosci., 19(5), 893-906. https://doi.org/10. 1162/jocn.2007.19.5.893

Greasley, A., \& Lamont, A. (2016). Musical preferences. In S. Hallam, I. Cross, \& M. Thaut (Eds.), The Oxford handbook of music psychology (2nd, pp. 263-281). Oxford University Press. https:// doi.org/10.1093/ oxfordhb/9780198722946.013.58

Grewe, O., Katzur, B., Kopiez, R., \& Altenmüller, E. (2011). Chills in different sensory domains: Frisson elicited by acoustical, visual, tactile and gustatory stimuli. Psychol. Music, 39(2), 220-239. https://doi.org/10.1177/ 0305735610362950

Grewe, O., Kopiez, R., \& Altenmüller, E. (2009a). The chill parameter: Goose bumps and shivers as promising measures in emotion research. Music Percept., 27(1), 61-74. https://doi.org/10.1525/mp.2009.27.1.61

Grewe, O., Kopiez, R., \& Altenmüller, E. (2009b). Chills as an indicator of individual emotional peaks. Ann. N.Y. Acad. Sci., 1169(1), 351-354. https://doi.org/10.1111/j.1749-6632.2009.04783.x

Grewe, O., Nagel, F., Kopiez, R., \& Altenmüller, E. (2007). Listening to music as a re-creative process: Physiological, psychological, and psychoacoustical correlates of chills and strong emotions. Music Percept., 24 (3), 297-314. https://doi.org/10.1525/mp.2007.24.3.297

Griffiths, T. D., Warren, J. D., Dean, J. L., \& Howard, D. (2004). "When the feeling's gone": A selective loss of musical emotion. J. Neurol. Neurosurg. Psychiatry, 72(2), 344-345. https://doi.org/10.1136/jnnp.2003.015586

Grunkina, V., Holtz, K., Klepzig, K., Neubert, J., Horn, U., Domin, M., Hamm, A. O., \& Lotze, M. (2017). The role of left hemispheric structures for emotional processing as a monitor of bodily reaction and felt chill - A 
case-control functional imaging study. Front. Hum. Neurosci., 10, 670. https://doi.org/10.3389/fnhum.2016.00670

Guhn, M., Hamm, A., \& Zentner, M. (2007). Physiological and musico-acoustic correlates of the chill response. Music Percept., 24 (5), 473-483. https: //doi.org/10.1525/mp.2007.24.5.473

Habibi, A., \& Damasio, A. (2014). Music, feelings, and the human brain. Psychomusicology Music Mind Brain, 24(1), 92-102. https://doi.org/10. 1037/pmu0000033

Halpern, D. L., Blake, R., \& Hillenbrand, J. (1986). Psychoacoustics of a chilling sound. Percept. Psychophys., 39(2), 77-80. https://doi.org/10.3758/ bf03211488

Hansen, N. C., \& Pearce, M. T. (2014). Predictive uncertainty in auditory sequence processing. Front. Psychol., 5, 1052. https://doi.org/10.3389/ fpsyg.2014.01052

Hansen, N. C., Vuust, P., \& Pearce, M. T. (2016). "If you have to ask, you'll never know": Effects of specialised stylistic expertise on predictive processing of music. PLOS ONE, 11(10), e0163584. https://doi.org/10.1371/ journal.pone.0163584

Hanslick, E. (1854). Vom Musikalisch-Schönen: Ein Beitrag zur Revision der ästhetik der Tonkunst. Rudolph Weigel.

Hargreaves, D. J. (2012). Musical imagination: Perception and production, beauty and creativity. Psychol. Music, 40(5), 539-557. https://doi.org/10.1177/ 0305735612444893

Hargreaves, D. J., \& North, A. C. (2010). Experimental aesthetics and liking for music. In P. N. Juslin \& J. A. Sloboda (Eds.), Handbook of music and emotion: Theory, research, applications (pp. 515-546). Oxford University Press. https://doi.org/10.1093/acprof:oso/9780199230143.003.0019

Harrison, L., \& Loui, P. (2014). Thrills, chills, frissons, and skin orgasms: Toward an integrative model of transcendent psychophysiological experiences in music. Front. Psychol., 5, 790. https://doi.org/10.3389/fpsyg.2014.00790

Harrison, N. R., \& Clark, D. P. A. (2016). The observing facet of trait mindfulness predicts frequency of aesthetic experiences evoked by the arts. Mindfulness, 7, 971-978. https://doi.org/10.1007/s12671-016-0536-6

Harvey, P.-O., Pruessner, J., Czechowska, Y., \& Lepage, M. (2007). Individual differences in trait anhedonia: A structural and functional magnetic resonance imaging study in non-clinical subjects. Mol. Psychiatry, 12, 767-775. https://doi.org/10.1038/sj.mp.4002021

Heathers, J. A. J., Fayn, K., Silvia, P. J., Tiliopoulos, N., \& Goodwin, M. S. (2018). The voluntary control of piloerection. PeerJ, 6, e5292. https: //doi.org/10.7717/peerj.5292

Hernández, M., Palomar-García, M.-Á., Nohales-Nieto, B., Olcina-Sempere, G., Villar-Rodríguez, E., Pastor, R., Ávila, C., \& Parcet, M.-A. (2019). Separate contribution of striatum volume and pitch discrimination to individual differences in music reward. Psychol. Sci., 30(9), 1352-1361. https://doi.org/10.1177/0956797619859339 
Hodges, D. A. (2016). Bodily responses to music. In S. Hallam, I. Cross, \& M. Thaut (Eds.), The Oxford handbook of music psychology (2nd, pp. 183196). Oxford University Press. https://doi.org/10.1093/oxfordhb/ 9780198722946.013.16

Honda, S., Ishikawa, Y., Konno, R., Imai, E., Nomiyama, N., Sakurada, K., Koumura, T., Kondo, H. M., Furukawa, S., Fujii, S., \& Nakatani, M. (2020). Proximal binaural sound can induce subjective frisson. Front. Psychol., 11, 316. https://doi.org/10.3389/fpsyg.2020.00316

Hunter, P. G., \& Schellenberg, E. G. (2010). Music and emotion. In M. R. Jones, R. R. Fay, \& A. N. Popper (Eds.), Music perception (pp. 129-164). Springer. https://doi.org/10.1007/978-1-4419-6114-3_5

Huron, D. (2006). Sweet anticipation: Music and the psychology of expectation. MIT Press.

Huron, D. (2016). Aesthetics. In S. Hallam, I. Cross, \& M. Thaut (Eds.), The Oxford handbook of music psychology (2nd, pp. 233-245). Oxford University Press. https://doi.org/10.1093/oxfordhb/9780198722946.013.19

Huron, D., \& Margulis, E. H. (2010). Musical expectancy and thrills. In P. N. Juslin \& J. A. Sloboda (Eds.), Handbook of music and emotion: Theory, research, applications (pp. 575-604). Oxford University Press. https: //doi.org/10.1093/acprof:oso/9780199230143.003.0021

Ishikawa, Y., Kawazoe, A., Chernyshov, G., Fujii, S., \& Nakatani, M. (2019). The thermal feedback influencer: Wearable thermal display for enhancing the experience of music listening. In H. Kajimoto, D. Lee, S.-Y. Kim, M. Konyo, \& K.-U. Kyung (Eds.), Proceedings of the International AsiaHaptics Conference, AsiaHaptics 2018: Haptic interaction (pp. 162168). Springer. https://doi.org/10.1007/978-981-13-3194-7_36

Jaimovich, J., Coghlan, N., \& Knapp, R. B. (2013). Emotion in motion: A study of music and affective response. In M. Aramaki, M. Barthet, R. Kronland-Martinet, \& S. Ystad (Eds.), Proceedings of the 9th International Symposium on Computer Music Modeling and Retrieval, CMMR 2012: From sounds to music and emotions (pp. 19-43). Springer. https://doi.org/10.1007/978-3-642-41248-6_2

Ji, Q., Janicke-Bowles, S. H., Leeuw, R. N. H. D., \& Oliver, M. B. (2019). The melody to inspiration: The effects of awe-eliciting music on approach motivation and positive well-being. Media Psychol., Advance online publication. https://doi.org/10.1080/15213269.2019.1693402

Jones, M. R., \& Boltz, M. (1989). Dynamic attending and responses to time. Psychol. Rev., 96(3), 459-491. https://doi.org/10.1037/0033-295x.96.3. 459

Juslin, P. N., Liljeström, S., Västfjäll, D., \& Lundqvist, L.-O. (2010). How does music evoke emotions? In P. N. Juslin \& J. A. Sloboda (Eds.), Handbook of music and emotion: Theory, research, applications (pp. 605642). Oxford University Press. https://doi.org/10.1093/acprof:oso/ 9780199230143.003.0022 
Juslin, P. N. (2013). From everyday emotions to aesthetic emotions: Towards a unified theory of musical emotions. Phys. Life Rev., 10(3), 235-266. https://doi.org/10.1016/j.plrev.2013.05.008

Juslin, P. N. (2016). Emotional reactions to music. In S. Hallam, I. Cross, \& M. Thaut (Eds.), The Oxford handbook of music psychology (2nd, pp. 197213). Oxford University Press. https://doi.org/10.1093/oxfordhb/ 9780198722946.013.17

Juslin, P. N. (2019). Musical emotions explained. Oxford University Press. https: //doi.org/10.1093/oso/9780198753421.001.0001

Juslin, P. N., Harmat, L., \& Eerola, T. (2014). What makes music emotionally significant? Exploring the underlying mechanisms. Psychol. Music, 42(4), 599-623. https://doi.org/10.1177/0305735613484548

Juslin, P. N., \& Västfjäll, D. (2008). Emotional responses to music: The need to consider underlying mechanisms. Behav. Brain Sci., 31(5), 559-575. https://doi.org/10.1017/s0140525x08005293

Kim, J., Seo, D. G., \& Cho, Y.-H. (2014). A flexible skin piloerection monitoring sensor. Appl. Phys. Lett., 104, 253502. https://doi.org/10.1063/1. 4881888

Klepzig, K., Horn, U., König, J., Holtz, K., Wendt, J., Hamm, A., \& Lotze, M. (2020). Brain imaging of chill reactions to pleasant and unpleasant sounds. Behav. Brain Res., 380, 112417. https://doi.org/10.1016/j.bbr. 2019.112417

Koelsch, S. (2010). Towards a neural basis of music-evoked emotions. Trends Cogn. Sci., 14 (3), 131-137. https://doi.org/10.1016/j.tics.2010.01.002

Koelsch, S. (2014). Brain correlates of music-evoked emotions. Nat. Rev. Neurosci., 15, 170-180. https://doi.org/10.1038/nrn3666

Koelsch, S., \& Jäncke, L. (2015). Music and the heart. Eur. Heart J., 36, 30433048. https://doi.org/10.1093/eurheartj/ehv430

Konečni, V. J. (2005). The aesthetic trinity: Awe, being moved, thrills. Bull. Psychol. Arts, 5(2), 27-44. https://doi.org/10.1037/e674862010-005

Konečni, V. J. (2007). Music and emotion: An empirical critique of a key issue in the philosophy of music. In A. Š. et al. (Ed.), Proceedings of the 5th International Conference "Person - Color - Nature - Music" (pp. 3140). Daugavpils University.

Konečni, V. J. (2008). Does music induce emotion? A theoretical and methodological analysis. Psychol. Aesthet. Creat. Arts, 2(2), 115-129. https: //doi.org/10.1037/1931-3896.2.2.115

Konečni, V. J. (2013). Empirical psycho-aesthetics and her sisters: Substantive and methodological issues-Part II. J. Aesthet. Educ., 47(1), 1-21. https://doi.org/10.5406/jaesteduc.47.1.0001

Konečni, V. J., Wanic, R. A., \& Brown, A. (2007). Emotional and aesthetic antecedents and consequences of music-induced thrills. Am. J. Psychol., 120 (4), 619-643. https://doi.org/10.2307/20445428

Kreibig, S. D. (2010). Autonomic nervous system activity in emotion: A review. Biol. Psychol., 84(3), 394-421. https://doi.org/10.1016/j.biopsycho. 2010.03.010 
Laeng, B., Eidet, L. M., Sulutvedt, U., \& Panksepp, J. (2016). Music chills: The eye pupil as a mirror to music's soul. Conscious. Cogn., 44, 161-178. https://doi.org/10.1016/j.concog.2016.07.009

Large, E. W., \& Jones, M. R. (1999). The dynamics of attending: How people track time-varying events. Psychol. Rev., 106(1), 119-159. https://doi. org/10.1037/0033-295x.106.1.119

Larsen, J. T., Berntson, G. G., Poehlmann, K. M., Ito, T. A., \& Cacioppo, J. T. (2008). The psychophysiology of emotions. In M. Lewis, J. M. HavilandJones, \& L. F. Barrett (Eds.), Handbook of emotions (3rd, pp. 180-195). Guilford Press.

Leder, H., Belke, B., Oeberst, A., \& Augustin, D. (2004). A model of aesthetic appreciation and aesthetic judgments. Br. J. Psychol., 94(4), 489-508. https://doi.org/10.1348/0007126042369811

Leder, H., \& Nadal, M. (2014). Ten years of a model of aesthetic appreciation and aesthetic judgments: The aesthetic episode - Developments and challenges in empirical aesthetics. Br. J. Psychol., 105(4), 443-464. https://doi.org/10.1111/bjop.12084

Lee, E.-J. (2008). The thrill effect in medical treatment: Thrill effect as a therapeutic tool in clinical health care (esp. music therapy). In S.-D. Yoo (Ed.), Proceedings of the EU-Korea Conference on Science and Technology. EKC2008 (pp. 477-483). Springer.

Levinson, J. (2006). Musical chills. In J. Levinson (Ed.), Contemplating art: Essays in aesthetics (pp. 220-236). Oxford University Press. https: //doi.org/10.1093/acprof:oso/9780199206179.003.0013

Levinson, J. (2009). The aesthetic appreciation of music. Br. J. Aesthet., 49(4), 415-425. https://doi.org/10.1093/aesthj/ayp043

Linnemann, A., Kreutz, G., Gollwitzer, M., \& Nater, U. M. (2018). Validation of the German version of the Music-Empathizing-Music-Systemizing (MEMS) inventory (short version). Front. Behav. Neurosci., 12, 153. https://doi.org/10.3389/fnbeh.2018.00153

Logothetis, N. K. (2008). What we can do and what we cannot do with fMRI. Nature, 453, 869-878. https://doi.org/10.1038/nature06976

Loui, P., Patterson, S., Sachs, M. E., Leung, Y., Zeng, T., \& Przysinda, E. (2017). White matter correlates of musical anhedonia: Implications for evolution of music. Front. Psychol., 8, 1664. https://doi.org/10.3389/fpsyg.2017. 01664

Mallik, A., Chanda, M. L., \& Levitin, D. J. (2017). Anhedonia to music and mu-opioids: Evidence from the administration of naltrexone. Sci. Rep., (7), 41952. https://doi.org/10.1038/srep41952

Maruskin, L. A., Thrash, T. M., \& Elliot, A. J. (2012). The chills as a psychological construct: Content universe, factor structure, affective composition, elicitors, trait antecedents, and consequences. J. Pers. Soc. Psychol., 103(1), 135-157. https://doi.org/10.1037/a0028117

Mas-Herrero, E., Marco-Pallares, J., Lorenzo-Seva, U., Zatorre, R. J., \& RodriguezFornells, A. (2013). Individual differences in music reward experiences. 
Music Percept., 31(2), 118-138. https://doi.org/10.1525/mp.2013.31.2. 118

Mas-Herrero, E., Zatorre, R. J., Rodriguez-Fornells, A., \& Marco-Pallarés, J. (2014). Dissociation between musical and monetary reward responses in specific musical anhedonia. Curr. Biol., 24(6), 699-704. https://doi. org/10.1016/j.cub.2014.01.068

Mathis, W. S., \& Han, X. (2017). The acute effect of pleasurable music on craving for alcohol: A pilot crossover study. J. Psychiatr. Res., 90, 143-147. https://doi.org/10.1016/j.jpsychires.2017.04.008

McCrae, R. R. (2007). Aesthetic chills as a universal marker of openness to experience. Motiv. Emot., 31(1), 5-11. https://doi.org/10.1007/s11031007-9053-1

McDermott, J. H. (2012). Auditory preferences and aesthetics: Music, voices, and everyday sounds. In R. J. Dolan \& T. Sharot (Eds.), Neuroscience of preference and choice: Cognitive and neural mechanisms (pp. 227-256). Academic Press. https://doi.org/10.1016/b978-0-12-381431-9.00020-6

McEvilly, D. K. (1999). Chills and tempo. Music Percept., 16(4), 457-462. https://doi.org/10.2307/40285804

Mencke, I., Omigie, D., Wald-Fuhrmann, M., \& Brattico, E. (2019). Atonal music: Can uncertainty lead to pleasure? Front. Neurosci., 12, 979. https://doi.org/10.3389/fnins.2018.00979

Menninghaus, W., Wagner, V., Hanich, J., Wassiliwizky, E., Kuehnast, M., \& Jacobsen, T. (2015). Towards a psychological construct of being moved. PLOS ONE, 10(6), e0128451. https://doi.org/10.1371/journal.pone. 0128451

Meyer, L. B. (1956). Emotion and meaning in music. Chicago University Press. https://doi.org/10.7208/chicago/9780226521374.001.0001

Miranda, R. A., \& Ullman, M. T. (2007). Double dissociation between rules and memory in music: An event-related potential study. NeuroImage, 38(2), 331-345. https://doi.org/10.1016/j.neuroimage.2007.07.034

Mlejnek, R. (2013). Physically experienced reactions and music: A questionnaire study of musicians and non-musicians. In G. Luck \& O. Brabant (Eds.), Proceedings of the 3rd International Conference on Music and Emotion, ICME3. University of Jyväskylä, Department of Music.

Mori, K., \& Iwanaga, M. (2014a). Music-induced chills as a strong emotional experience. Jpn. J. Psychol., 85(5), 495-509. https://doi.org/10.4992/ jjpsy.85.13401

Mori, K., \& Iwanaga, M. (2014b). Resting physiological arousal is associated with the experience of music-induced chills. Int. J. Psychophysiol., 93(2), 220-226. https://doi.org/10.1016/j.ijpsycho.2014.05.001

Mori, K., \& Iwanaga, M. (2015). General reward sensitivity predicts intensity of music-evoked chills. Music Percept., 32(5), 484-492. https://doi.org/10. $1525 / \mathrm{mp} .2015 .32 .5 .484$

Mori, K., \& Iwanaga, M. (2017). Two types of peak emotional responses to music: The psychophysiology of chills and tears. Sci. Rep., 7, 46063. https://doi.org/10.1038/srep46063 
Müllensiefen, D., Gingras, B., Musil, J., \& Stewart, L. (2014). The musicality of non-musicians: An index for assessing musical sophistication in the general population. PLOS ONE, $9(2)$, e89642. https://doi.org/10.1371/ journal.pone.0089642

Nagel, F., Kopiez, R., Grewe, O., \& Altenmüller, E. (2007). EMuJoy: Software for continuous measurement of perceived emotions in music. Behav. Res. Methods, 39(2), 283-290. https://doi.org/10.3758/bf03193159

Nagel, F., Kopiez, R., Grewe, O., \& Altenmüller, E. (2008). Psychoacoustical correlates of musically induced chills. Music. Sci., 12(1), 101-113. https: //doi.org/10.1177/102986490801200106

Neidlinger, K., Truong, K. P., Telfair, C., Feijs, L., Dertien, E., \& Evers, V. (2017). AWElectric: That gave me goosebumps, did you feel it too? In R. Peiris (Ed.), Proceedings of the Eleventh International Conference on Tangible, Embedded, and Embodied Interaction, TEI'17 (pp. 315-324). Association for Computing Machinery. https://doi.org/10.1145/3024969.3025004

Nusbaum, E. C., \& Silvia, P. J. (2011). Shivers and timbres: Personality and the experience of chills from music. Soc. Psychol. Pers. Sci., 2(2), 199-204. https://doi.org/10.1177/1948550610386810

Nusbaum, E. C., Silvia, P. J., Beaty, R. E., Burgin, C. J., Hodges, D. A., \& Kwapil, T. R. (2014). Listening between the notes: Aesthetic chills in everyday music listening. Psychol. Aesthet. Creat. Arts, 8(1), 104-109. https://doi.org/10.1037/a0034867

Nusbaum, E. C., Silvia, P. J., Beaty, R. E., Burgin, C. J., \& Kwapil, T. R. (2015). Turn that racket down! Physical anhedonia and diminished pleasure from music. Empir. Stud. Arts, 33(2), 228-243. https://doi.org/10.1177/ 0276237415597392

Orne, M. T. (1962). On the social psychology of the psychological experiment: With particular reference to demand characteristics and their implications. Am. Psychol., 17(11), 776-783. https://doi.org/10.1037/h0043424

Panksepp, J. (1995). The emotional sources of "chills" induced by music. Music Percept., 13(2), 171-207. https://doi.org/10.2307/40285693

Panksepp, J. (2009). The emotional antecedents to the evolution of music and language. Music. Sci., 13(Suppl. 2), 229-259. https://doi.org/10.1177/ 1029864909013002111

Panksepp, J., \& Bernatzky, G. (2002). Emotional sounds and the brain: The neuro-affective foundations of musical appreciation. Behav. Process., 60(2), 133-155. https://doi.org/10.1016/s0376-6357(02)00080-3

Panzarella, R. (1980). The phenomology of aesthetic peak experiences. J. Humanist. Psychol., 20(1), 69-85. https://doi.org/10.1177/002216788002000105

Park, K. S., Hass, C. J., Fawver, B., Lee, H., \& Janelle, C. M. (2019). Emotional states influence forward gait during music listening based on familiarity with music selections. Hum. Mov. Sci., 66, 53-62. https://doi.org/10. 1016/j.humov.2019.03.004

Pearce, M. T. (2018). Statistical learning and probabilistic prediction in music cognition: Mechanisms of stylistic enculturation. Ann. N.Y. Acad. Sci., 1423(1), 378-395. https://doi.org/10.1111/nyas.13654 
Pearce, M. T., \& Wiggins, G. A. (2012). Auditory expectation: The information dynamics of music perception and cognition. Top. Cogn. Sci., 4(4), 625-652. https://doi.org/10.1111/j.1756-8765.2012.01214.x

Pelowski, M., Markey, P., \& Leder, H. (2018). Chills, aesthetic experience, and new versus old knowledge - What do chills actually portend? Comment on "Physics of mind: Experimental confirmations of theoretical predictions" by Schoeller et al. Phys. Life Rev., 25, 83-87. https://doi. org/10.1016/j.plrev.2018.03.014

Pelowski, M., Markey, P. S., Forster, M., Gerger, G., \& Leder, H. (2017). Move me, astonish me... delight my eyes and brain: The Vienna Integrated Model of top-down and bottom-up processes in Art Perception (VIMAP) and corresponding affective, evaluative, and neurophysiological correlates. Phys. Life Rev., 21, 80-125. https://doi.org/10.1016/j.plrev.2017.02.003

Poldrack, R. A. (2011). Inferring mental states from neuroimaging data: From reverse inference to large-scale decoding. Neuron, 72 (5), 692-697. https: //doi.org/10.1016/j.neuron.2011.11.001

Polo, M. J. (2017). Chill responses to post-tonal music: Musical structures and physiological reactions (Doctoral dissertation). University of Florida.

Quesnel, D., \& Riecke, B. E. (2018). Are you awed yet? How virtual reality gives us awe and goose bumps. Front. Psychol., 9, 2158. https://doi.org/10. 3389/fpsyg.2018.02158

Quiroga-Martinez, D. R., Hansen, N. C., Højlund, A., Pearce, M. T., Brattico, E., \& Vuust, P. (2019). Musical prediction error responses similarly reduced by predictive uncertainty in musicians and non-musicians. Eur. J. Neurosci., 51(11), 2250-2269. https://doi.org/10.1111/ejn.14667

Rickard, N. S. (2004). Intense emotional responses to music: A test of the physiological arousal hypothesis. Psychol. Music, 32(4), 371-388. https: //doi.org/10.1177/0305735604046096

Sachs, M. E., Ellis, R. J., Schlaug, G., \& Loui, P. (2016). Brain connectivity reflects human aesthetic responses to music. Soc. Cogn. Affect. Neurosci., 11(6), 884-891. https://doi.org/10.1093/scan/nsw009

Sachs, M. E., Habibi, A., \& Damasio, H. (2018). Reflections on music, affect, and sociality. In J. F. Christensen \& A. Gomila (Eds.), The arts and the brain: Psychology and physiology beyond pleasure (pp. 153-172). Academic Press. https://doi.org/10.1016/bs.pbr.2018.03.009

Saffran, J. R., Johnson, E. K., Aslin, R. N., \& Newport, E. L. (1999). Statistical learning of tone sequences by human infants and adults. Cognition, 70 (1), 27-52. https://doi.org/10.1016/s0010-0277(98)00075-4

Salimpoor, V. N., Benovoy, M., Larcher, K., Dagher, A., \& Zatorre, R. J. (2011). Anatomically distinct dopamine release during anticipation and experience of peak emotion to music. Nat. Neurosci., 14(2), 257-262. https://doi.org/10.1038/nn.2726

Salimpoor, V. N., Benovoy, M., Longo, G., Cooperstock, J. R., \& Zatorre, R. J. (2009). The rewarding aspects of music listening are related to degree of emotional arousal. PLOS ONE, 4(10), e7487. https://doi.org/10.1371/ journal.pone.0007487 
Salimpoor, V. N., Zald, D. H., Zatorre, R. J., Dagher, A., \& McIntosh, A. R. (2015). Predictions and the brain: How musical sounds become rewarding. Trends Cogn. Sci., 19(2), 86-91. https://doi.org/10.1016/j.tics.2014.12. 001

Salimpoor, V. N., \& Zatorre, R. J. (2013). Neural interactions that give rise to musical pleasure. Psychol. Aesthet. Creat. Arts, 7(1), 62-75. https: //doi.org/10.1037/a0031819

Satoh, M., Kato, N., Tabei, K.-i., Nakano, C., Abe, M., Fujita, R., Kida, H., Tomimoto, H., \& Kondo, K. (2016). A case of musical anhedonia due to right putaminal hemorrhage: A disconnection syndrome between the auditory cortex and insula. Neurocase, 22(6), 518-525. https://doi.org/ 10.1080/13554794.2016.1264609

Schaefer, H.-E. (2017). Music-evoked emotions - Current studies. Front. Neurosci., 11, 600. https://doi.org/10.3389/fnins.2017.00600

Schäfer, T., \& Mehlhorn, C. (2017). Can personality traits predict musical style preferences? A meta-analysis. Pers. Individ. Differ., 116, 265-273. https://doi.org/10.1016/j.paid.2017.04.061

Schäfer, T., \& Sedlmeier, P. (2010). What makes us like music? Determinants of music preference. Psychol. Aesthet. Creat. Arts, 4(4), 223-234. https: //doi.org/10.1037/a0018374

Schäfer, T., \& Sedlmeier, P. (2011). Does the body move the soul? The impact of arousal on music preference. Music Percept., 29(1), 37-50. https: //doi.org/10.1525/mp.2011.29.1.37

Scherer, K. R. (2009). The dynamic architecture of emotion: Evidence for the component process model. Cogn. Emot., 23(7), 1307-1351. https://doi. org $/ 10.1080 / 02699930902928969$

Scherer, K. R., Zentner, M. R., \& Schacht, A. (2001). Emotional states generated by music: An exploratory study of music experts. Music. Sci., 5 (Suppl. 1), 149-171. https://doi.org/10.1177/10298649020050s106

Schoeller, F. (2015). Knowledge, curiosity, and aesthetic chills. Front. Psychol., 6, 1546. https://doi.org/10.3389/fpsyg.2015.01546

Schoeller, F., \& Eskinazi, M. (2019). Psychologie du frisson esthétique. Psychol. Fr., 64, 305-312. https://doi.org/10.1016/j.psfr.2017.11.003

Schoeller, F., Eskinazi, M., \& Garreau, D. (2018). Dynamics of the knowledge instinct: Effects of incoherence on the cognitive system. Cogn. Syst. Res., 48, 85-91. https://doi.org/10.1016/j.cogsys.2017.07.005

Schoeller, F., Haar, A. J. H., Jain, A., \& Maes, P. (2019). Enhancing human emotions with interoceptive technologies. Phys. Life Rev., 31, 310-319. https://doi.org/10.1016/j.plrev.2019.10.008

Schoeller, F., \& Perlovsky, L. (2016). Aesthetic chills: Knowledge-acquisition, meaning-making, and aesthetic emotions. Front. Psychol., 7, 1093. https: //doi.org/10.3389/fpsyg.2016.01093

Schoeller, F., Perlovsky, L., \& Arseniev, D. (2018). Physics of mind: Experimental confirmations of theoretical predictions. Phys. Life Rev., 25, 45-68. https: //doi.org/10.1016/j.plrev.2017.11.021 
Schubert, E. (2013). Emotion felt by the listener and expressed by the music: Literature review and theoretical perspectives. Front. Psychol., 4, 837. https://doi.org/10.3389/fpsyg.2013.00837

Schubert, E., North, A. C., \& Hargreaves, D. J. (2016). Aesthetic experience explained by the affect-space framework. Empir. Music. Rev., 11(3-4), 330-345. https://doi.org/10.18061/emr.v11i3-4.5115

Schubert, T. W., Zickfeld, J. H., Seibt, B., \& Fiske, A. P. (2018). Moment-tomoment changes in feeling moved match changes in closeness, tears, goosebumps, and warmth: Time series analyses. Cogn. Emot., 32(1), 174-184. https://doi.org/10.1080/02699931.2016.1268998

Schurtz, D. R., Blincoe, S., Smith, R. H., Powell, C. A. J., Combs, D. J. Y., \& Kim, S. H. (2012). Exploring the social aspects of goose bumps and their role in awe and envy. Motiv. Emot., 36, 205-217. https: //doi.org/10.1007/s11031-011-9243-8

Seibt, B., Schubert, T. W., Zickfeld, J. H., \& Fiske, A. P. (2017). Interpersonal closeness and morality predict feelings of being moved. Emotion, 17(3), 389-394. https://doi.org/10.1037/emo0000271

Seibt, B., Schubert, T. W., Zickfeld, J. H., Zhu, L., Arriaga, P., Simão, C., Nussinson, R., \& Fiske, A. P. (2018). Kama muta: Similar emotional responses to touching videos across the United States, Norway, China, Israel, and Portugal. J. Cross-Cult. Psychol., 49(3), 418-435. https: //doi.org/10.1177/0022022117746240

Silvia, P. J., Fayn, K., Nusbaum, E. C., \& Beaty, R. E. (2015). Openness to experience and awe in response to nature and music: Personality and profound aesthetic experiences. Psychol. Aesthet. Creat. Arts, 9(4), 376384. https://doi.org/10.1037/aca0000028

Silvia, P. J., \& Nusbaum, E. C. (2011). On personality and piloerection: Individual differences in aesthetic chills and other unusual aesthetic experiences. Psychol. Aesthet. Creat. Arts, 5(3), 208-214. https://doi.org/10.1037/ a0021914

Sloboda, J. A. (1991). Music structure and emotional response: Some empirical findings. Psychol. Music, 19(2), 110-120. https://doi.org/10.1177/ 0305735691192002

Solberg, R. T., \& Dibben, N. (2019). Peak experiences with electronic dance music: Subjective experiences, physiological responses, and musical characteristics of the break routine. Music Percept., 36(4), 371-389. https: //doi.org/10.1525/mp.2019.36.4.371

Starcke, K., von Georgi, R., Tiihonen, T. M., Laczika, K.-F., \& Reuter, C. (2019). Don't drink and chill: Effects of alcohol on subjective and physiological reactions during music listening and their relationships with personality and listening habits. Int. J. Psychophysiol., 142, 25-32. https://doi.org/ 10.1016/j.ijpsycho.2019.06.001

Stark, E. A., Vuust, P., \& Kringelbach, M. L. (2018). Music, dance, and other art forms: New insights into the links between hedonia (pleasure) and eudaimonia (well-being). In J. F. Christensen \& A. Gomila (Eds.), The 
arts and the brain: Psychology and physiology beyond pleasure (pp. 129152). Academic Press. https://doi.org/10.1016/bs.pbr.2018.03.019

Steinbeis, N., Koelsch, S., \& Sloboda, J. A. (2006). The role of harmonic expectancy violations in musical emotions: Evidence from subjective, physiological, and neural responses. J. Cogn. Neurosci., 18(8), 1380-1393. https://doi.org/10.1162/jocn.2006.18.8.1380

Strick, M., de Bruin, H. L., de Ruiter, L. C., \& Jonkers, W. (2015). Striking the right chord: Moving music increases psychological transportation and behavioral intentions. J. Exp. Psychol. Appl., 21(1), 57-72. https: //doi.org/10.1037/xap0000034

Sumpf, M., Jentschke, S., \& Koelsch, S. (2015). Effects of aesthetic chills on a cardiac signature of emotionality. PLOS ONE, 10(6), e0130117. https: //doi.org/10.1371/journal.pone.0130117

Sutherland, M. E., Grewe, O., Egermann, H., Nagel, F., Kopiez, R., \& Altenmüller, E. (2009). The influence of social situations on music listening. Ann. N.Y. Acad. Sci., 1169, 363-367. https://doi.org/10.1111/j.17496632.2009.04764.x

Teki, S., Grube, M., Kumar, S., \& Griffiths, T. D. (2011). Distinct neural substrates of duration-based and beat-based auditory timing. J. Neurosci., 31 (10), 3805-3812. https://doi.org/10.1523/jneurosci.5561-10.2011

Tihanyi, B. T. (2016). A zenei bizsergés pszichofiziológiai háttere és terápiás felhasználása. Mentálhigiéné Pszichoszomatika, 17(1), 19-36. https: //doi.org/10.1556/0406.17.2016.1.2

Verhaeghen, P. (2018). Once more, with feeling: The role of familiarity in the aesthetic response. Psychol. Rec., 68, 379-384. https://doi.org/10.1007/ s40732-018-0312-1

Vuoskoski, J. K., \& Eerola, T. (2017). The pleasure evoked by sad music is mediated by feelings of being moved. Front. Psychol., 8, 439. https: //doi.org/10.3389/fpsyg.2017.00439

Vuust, P., \& Kringelbach, M. L. (2010). The pleasure of music. In M. L. Kringelbach \& K. C. Berridge (Eds.), Pleasures of the brain (pp. 255-269). Oxford University Press.

Warrenburg, L. A. (2020). Choosing the right tune: A review of music stimuli used in emotion research. Music Percept., 37(3), 240-258. https://doi. org $/ 10.1525 / \mathrm{mp} .2020 .37 .3 .240$

Wassiliwizky, E., Jacobsen, T., Heinrich, J., Schneiderbauer, M., \& Menninghaus, W. (2017). Tears falling on goosebumps: Co-occurence of lacrimation and emotional piloerection indicates a psychophysiological climax in emotional arousal. Front. Psychol., 8, 41. https://doi.org/10.3389/fpsyg. 2017.00041

Wassiliwizky, E., Koelsch, S., Wagner, V., Jacobsen, T., \& Menninghaus, W. (2017). The emotional power of poetry: Neural circuitry, psychophysiology and compositional principles. Soc. Cogn. Affect. Neurosci., 12(8), 1129-1240. https://doi.org/10.1093/scan/nsx069 
Wassiliwizky, E., Wagner, V., Jacobsen, T., \& Menninghaus, W. (2015). Artelicited chills indicate states of being moved. Psychol. Aesthet. Creat. Arts, 9(4), 405-416. https://doi.org/10.1037/aca0000023

Weth, K., Raab, M. H., \& Carbon, C.-C. (2015). Investigating emotional responses to self-selected sad music via self-report and automated facial analysis. Music. Sci., 19(4), 412-432. https://doi.org/10.1177/ 1029864915606796

Williams, P. G., Johnson, K. T., Curtis, B. J., King, J. B., \& Anderson, J. S. (2018). Individual differences in aesthetic engagement are reflected in resting-state fMRI connectivity: Implications for stress resilience. $\mathrm{Neu}$ roImage, 179, 156-165. https://doi.org/10.1016/j.neuroimage.2018.06. 042

Zatorre, R. J. (2003). Music and the brain. Ann. N.Y. Acad. Sci., 999(1), 4-14. https://doi.org/10.1196/annals.1284.001

Zatorre, R. J. (2015). Musical pleasure and reward: Mechanisms and dysfunction. Ann. N.Y. Acad. Sci., 1337(1), 202-211. https://doi.org/10.1111/nyas. 12677

Zatorre, R. J., \& Salimpoor, V. N. (2013). From perception to pleasure: Music and its neural substrates. Proc. Natl. Acad. Sci. U.S.A., 110 (Suppl. 2), 10430-10437. https://doi.org/10.1073/pnas.1301228110

Zentner, M., \& Eerola, T. (2010). Self-report measures and models. In P. N. Juslin \& J. A. Sloboda (Eds.), Handbook of music and emotion: Theory, research, applications (pp. 187-221). Oxford University Press. https: //doi.org/10.1093/acprof:oso/9780199230143.003.0008

Zentner, M., Grandjean, D., \& Scherer, K. R. (2008). Emotions evoked by the sound of music: Characterization, classification, and measurement. Emotion, 8(4), 494-521. https://doi.org/10.1037/1528-3542.8.4.494

Zickfeld, J. H., Schubert, T. W., Seibt, B., Blomster, J. K., Arriaga, P., Basabe, N., Blaut, A., Caballero, A., Carrera, P., Dalğar, I., Ding, Y., Dumont, K., Gaulhofer, V., Gračanin, A., Gyenis, R., Hu, C.-P., Kardum, I., Lazarević, L., Mathew, L., ... Fiske, A. P. (2019). Kama muta: Conceptualizing and measuring the experience often labelled being moved across 19 nations and 15 languages. Emotion, 19(3), 402-424. https://doi.org/10. $1037 / \mathrm{emo} 0000450$

Zickfeld, J. H., Schubert, T. W., Seibt, B., \& Fiske, A. P. (2017). Empathic concern is part of a more general communal emotion. Front. Psychol., 8 , 723. https://doi.org/10.3389/fpsyg.2017.00723

Zickfeld, J. H., Schubert, T. W., Seibt, B., \& Fiske, A. P. (2019). Moving through the literature: What is the emotion often denoted being moved? Emot. Rev., 11(2), 123-139. https://doi.org/10.1177/1754073918820126 